\title{
Subtilase cytotoxin induces apoptosis in HeLa cells by mitochondrial permeabilization via activation of Bax/Bak, independent of C/EBF-homologue protein (CHOP), Ire1 $\alpha$ or JNK signaling
}

Kinnosuke Yahiro ${ }^{1}$, Naoko Morinaga ${ }^{1}$, Joel Moss ${ }^{2}$, and Masatoshi Noda ${ }^{1}$

${ }^{1}$ Department of Molecular Infectiology, Graduate School of Medicine, Chiba University 1-8-1 Inohana Chuo-ku, Chiba 260-8670, Japan. ${ }^{2}$ Translational Medicine Branch, NHLBI, $\mathrm{NIH}$, Bethesda, Maryland, USA.

Running title: Subtilase cytotoxin induces Bax/Bak dependent apoptosis Address correspondence to: Department of Molecular Infectiology, Graduate School of Medicine, Chiba University 1-8-1 Inohana Chuo-ku, Chiba 260-8670, Japan. Tel: 81-43-226-2049, Fax: 81-43-226-2049, E-mail: yahirok@ faculty.chiba-u.jp

Footnote

a, This work was supported by grants-in-aid for Scientific Research from Japan Society for the Promotion of Science and for Improvement of Research Environment for Young Researchers from Japan Science and Technology Agency.

$\mathrm{b}$, This manuscript has not been published and is not under consideration for publication elsewhere. All the authors have read the manuscript and have approved this submission. 


\begin{abstract}
Subtilase cytotoxin (SubAB) is an $\mathrm{AB}_{5}$ cytotoxin produced by some strains of Shiga-toxigenic Escherichia coli. The A subunit is a subtilase-like serine protease and cleaves an endoplasmic reticulum (ER) chaperone, BiP, leading to transient inhibition of protein synthesis and cell cycle arrest at $G_{1}$ phase, and inducing caspase-dependent apoptosis via mitochondrial membrane damage in Vero cells. Here we investigated the mechanism of mitochondrial permeabilization in HeLa cells. SubAB-induced cytochrome $c$ release into cytosol did not depend on mitochondrial permeability transition pore (PTP), since cyclosporine A did not suppress cytochrome $c$ release. SubAB did not change the expression of anti-apoptotic Bcl-2 or Bcl-XL and pro-apoptotic Bax or Bak, but triggered Bax and Bak conformational changes and association of Bax with Bak. Silencing using siRNA of both bax and bak genes, but not bax, bak, or bim alone, resulted in reduction of cytochrome $c$ release, caspase-3 activation, DNA ladder formation and cytotoxicity, indicating that Bax and Bak were involved in apoptosis. SubAB activated ER transmembrane transducers, Ire1 $\alpha$, and cJun N-terminal kinase (JNK), and induced C/EBF-homologue protein (CHOP). To investigate whether these signals were involved in cytochrome $c$ release by Bax activation, we silenced ire1 $\alpha$,jnk or chop; however, silencing did not decrease SubAB-induced cytochrome $c$ release, suggesting that these signals were not necessary for SubAB-induced mitochondrial permeabilization by Bax activation.
\end{abstract}

Keywords; Subtilase cytotoxin, ER stress, apoptosis, Bax, Bak,

\title{
1. Introduction
}


A new member of the $\mathrm{AB}_{5}$ toxin family, named subtilase cytotoxin (SubAB), was identified in E. coli O113:H21 strain 98NK2, which produced Stx2 and was responsible for an outbreak of hemolytic uremic syndrome (HUS) [1]. SubAB A subunit, a $35 \mathrm{kDa}$ protein, shares sequence homology with a subtilase-like serine protease of Bacillus anthracis and the toxin was named 'subtilase cytotoxin'. The A subunit cleaves at a specific single site of ER chaperone BiP[2]. B subunits bind with high specificity to $N$-glycosylated membrane proteins [3] and in particular, glycans terminating in the sialic acid $N$-glycolylneuraminic acid [4]. $\alpha 2 \beta 1$ integrin has been shown to be one of the receptors responsible for vacuolating activity of B subunits [3].

SubAB is lethal for mice, causing extensive microvascular thrombosis as well as necrosis in the brain, kidney and liver, and apoptosis in the spleen, kidney and liver [5]. These findings are similar to the histopathologic, biochemical and hematologic changes seen in human HUS. Mutagenesis of a critical active site Ser residue in SubA abolished the toxicity, indicating that BiP cleavage is central to the mechanism of action of SubAB. SubAB cytotoxicity of Vero and HeLa cells correlated with A subunit enzymatic activity[1, 6].

BiP, a target of SubAB, localizes mainly in the ER lumen. ER is the site for synthesis, folding, modification and trafficking of secreted and cell-surface proteins. BiP is a master regulator of ER function and homeostasis [7]. Cleavage of BiP by SubA induces ER stress, which was demonstrated by activation of double-stranded RNA-activated protein kinase-like ER kinase (PERK) and eukaryotic initiation factor-2 $\alpha$ (eIF2 $\alpha$ ), leading to transient inhibition of protein synthesis, and induction of $\mathrm{CHOP}$, with cell cycle arrest in $\mathrm{G}_{1}$ phase as a result of down-regulation of cyclin D1 [8]. The other membrane stress sensors, ATF6 and Ire1 $\alpha$, were also activated by SubAB [9]. To avoid cell death, ER chaperone proteins eliminate the stress; when this fails, cell death occurs. In SubAB-treated cells, BiP, a chaperone protein, was cleaved and inactivated, resulting in continuous ER stress, thus leading to cell death. Lass et al. [10] explored the mechanism of ER stress induced by SubAB in human cells lines, focusing on its effects on ER-associated degradation. In a previous report, we showed that in Vero cells SubAB induced caspase-dependent apoptosis via mitochondrial membrane damage [11]. We did not clarify the mechanism by which signal SubAB induced mitochondrial permeabilization and apoptosis.

Bcl-2 family member proteins strictly control cell death in response to diverse stimuli, e. g., DNA damage, viral infection, growth factor deprivation [12, 13]. The family members are grouped into two classes. One class (pro-survival proteins) inhibits apoptosis, whereas a second class (pro-apoptotic proteins), which promotes apoptosis, includes the death mediators, Bax 
and Bak, and other proteins. These proteins possess a conserved BH-3 domain, which can bind and regulate the pro-survival Bcl-2 proteins and promote apoptosis. In this report, we show in HeLa cells that mitochondrial cytochrome $c$ release was dependent on Bax/Bak activation. We further report that signaling from CHOP, Ire1 $\alpha$, or JNK, which were activated by SubAB-induced BiP cleavage, did not suppress cytochrome $c$ release by Bax activation, although those mediators were involved in ER-stress induced apoptosis in other cell types using different death stimuli $[14,15]$.

\section{Results and Discussion}

\subsection{SubAB induces apoptosis in HeLa cells by intrinsic pathway via mitochondria.}

SubAB induces apoptotic cell death of HeLa cells, similar to that seen with Vero cells [11]. The $50 \%$ inhibitory dose in HeLa cells was, however, $\sim 50 \mathrm{ng} / \mathrm{ml}$, which was $\sim 100$ times greater than that needed with Vero cells. 100 200 ng/ml of SubAB induced activation of caspases-3, -8 , and -9 and PARP cleavage (Fig. 1A). As we previously reported, SubAB-induced apoptosis was dependent on BiP cleavage, which was occurred within 60 min (Fig. 1B); the catalytically inactive mutant, SubAB(S272A), did not cleave BiP (Fig. 1B) and did not induce apoptosis. SubAB-induced apoptosis resulted from activation of the intrinsic pathway in which cytochrome $c$ release from mitochondria triggers the formation of the apoptosome composed of Apaf-1 and procaspase-9. Activated caspase-9 then stimulated activation of caspase- 3 . General caspase inhibitor Z-VAD-FMK (VAD) suppressed apoptosis, with reduction in Annexin-V binding [11]. VAD and inhibitors specific to caspase-3, 8 and 9, however, did not suppress cytochrome $c$ release in HeLa cells (Fig.1C), suggesting that not only cytochrome $c$ release but also caspase activation is critical for SubAB-induced cell damage by apoptosis. It may also suggest that cytochrome c release by SubAB may occur upstream of caspase activation.

\subsection{SubAB induces mitochondrial membrane damage in a Bax/Bak-dependent manner} Permeabilization of mitochondria outer membrane (OMM) can be achieved by several different mechanisms, including pore formation by pro-apoptotic Bcl-2 family proteins. We first investigated the levels of Bcl-2 family proteins (Fig. 2). Expression levels of pro-survival family members, Bcl-2 and Bcl-XL, were not changed by incubation with SubAB for up to $30 \mathrm{~h}$. Mcl-1 in contrast was decreased. SubAB(S272A) did not induce Mcl-1 decrease. Mcl-1 is primarily localized to the outer mitochondrial membrane and promotes cell survival by suppressing cytochrome $c$ release from mitochondria via heterodimerization with and neutralization of pro-apoptotic Bcl-2 family members 
including Bak [16, 17]. Therefore the decrease in Mcl-1 may be a factor contributing to induction of apoptosis. We investigated the effect of Mcl-1 overexpression (Supplementary Figure S1). In cells overexpressing Mcl-1, slight suppression of cytochrome $c$ release was observed but it was not significant. Caspase-3 level was not suppressed. Levels of cell death mediators, Bax and Bak, were not different (Fig. 2). These data suggested that SubAB-induced cell death was not caused by increased amounts of pro-apoptotic proteins, Bax and Bak, or by reduction of pro-survival proteins, Bcl-2 and Bcl-XL. The level of a BH3-only protein, Bim, was not increased, however, the protein was dephosphorylated in a time-dependent manner, which was determined by its faster mobility on SDS-PAGE (Fig. 2). SubAB(S272A) did not induce the dephosphorylation of Bim. A role for Bim in apoptosis was proposed recently [18-20] ; it has been suggested that ER stress increases dephosphorylated Bim, which inhibits Bcl-2, a pro-survival protein, leading to Bax/Bak activation and cell death [21]. To confirm whether SubAB toxicity follows those pathways, we investigated whether in cells with knockdown of Bim using Bim siRNA, cytochrome $c$ release by SubAB was suppressed. We observed, however, that cytochrome $c$ release was increased (Supplementary Figure S2). These data suggested that Bim alone was not responsible for induce SubAB-induced mitochondrial damage. SubAB but not mutant SubAB(S272A) decreased another regulator, Bad, which was found to induce apoptosis by suppressing Bcl-XL activity [22] or by dephosphorylation of Bad which sensitizes the mitochondrial permeability transition pore (PTP) to $\mathrm{Ca}^{2+}$, independent of Bax or Bak, through a Bcl-xL-dependent process [23]. Bad overexpression induces apoptosis in JEG-3 cells [24]. Therefore, decrease in both phosphorylated- and dephosphorylated-Bad (Fig. 2) may inhibit cell death following SubAB treatment. Therefore, involvement of Bad in SubAB-induced apoptosis seems unlikely.

Interaction of pro-apoptotic Bcl-2 family members with components of the PTP, which consists of voltage-dependent anion channel, the adenine nucleotide translocator, and cyclophilin D, results in mitochondrial depolarization and swelling, followed by mitochondrial outer membrane rupture and release of the inner membrane content [23]. This PTP formation can be prevented by cyclosporine A $[25,26]$. In our system, cyclosporine A enhanced SubAB-induced cytochrome $c$ release (Fig. 3), suggesting that SubAB-induced mitochondrial permeabilization did not depend on PTP.

Total Bax and Bak content did not change by SubAB-treatment (Fig. 2). It is known, however, that in response to apoptotic stimuli, Bax translocates from cytosol to mitochondria [27], and integrates into the OMM as mono- or hetero oligomers with Bak, leading to pore formation [28-30]. We examined whether subcellular localization of Bax and Bak was changed by SubAB. Bax was found, however, in both cytosolic and membrane fractions in untreated 
control cells and no increase of Bax in the membrane fraction, which contains mitochondria, was observed following treatment with SubAB. Thus, in HeLa cells, Bax may be localized not only in cytosol but also in mitochondria or other membranes. In contrast, Bak was found only in membrane fractions (data not shown). SubAB, however, induced Bax conformational changes in a time-dependent manner, by flow cytometric analysis using conformation-specific Bax antibody (clone 3) (Fig. 4A). In contrast, HeLa cells incubated without toxin did not show any conformational change of Bax (data not shown). We further investigated Bax and Bak association in SubAB-treated cells using immunoprecipitation with conformation-specific Bax antibody (Fig. 4B). Conformationally changed Bax was only found in SubAB-treated cells but not in control without toxin or SubAB(S272A)-treated cells; Bak was precipitated by antibody against conformation-specific Bax, suggesting complex formation of Bax and Bak (Fig. 4B, middle blot). Conformation-specific Bak was clearly increased in SubAB-treated cells compared to control or SubAB(S272A)-treated cells (Fig. 4B, lower blot). To evaluate a Bax effect on cytochrome $c$ release, we knocked down Bax with siRNA. In cells in which Bax level was decreased, however, no suppression of cytochrome $c$ release was observed (Fig. 5 and Supplementary Figure S2). In contrast, in cells in which both Bax and Bak were knocked down (Fig. Supplementary Figure S3), cytochrome $c$ release and activation of caspase-3 by SubAB were significantly suppressed (Fig. 5A); in agreement with this result, SubAB-induced DNA fragmentation and SubAB cytotoxicity were also suppressed (Fig. 5B and C).

\subsection{Pathway to induce Bax/Bak activation after BiP cleavage}

Above data showed that Bax/Bak were involved in SubAB-induced cytochrome $c$ release. However, how Bax/Bak were activated was not known. Several pathways have been implicated in ER stress-induced apoptosis [14]. A transcription factor, CHOP, which is induced by ER stress at the transcript level, was reported to induce apoptosis mediated by downregulation of Bcl-2 [31], by upregulation of Bim [21], and by translocation of Bax from cytosol to mitochondria [32]. Apoptosis induction by $\mathrm{CHOP}$ was demonstrated with $\mathrm{CHOP}^{-/-}$mice [33]. In HeLa cells, SubAB caused CHOP induction in a time-dependent manner (Fig. 6A) similar to a previous report [10]. To investigate whether CHOP activation was correlated with SubAB-induced apoptosis, chop was silenced with siRNA. In cells in which CHOP induction by SubAB was suppressed (Fig. 7A), SubAB-induced cytochrome $c$ release at $30 \mathrm{~h}$ was not suppressed but rather increased (not significant) but no difference was observed at $34 \mathrm{~h}$ (Fig. 7B). The other is a recently reported pathway in which p53 activated BH-3-only protein PUMA and NOXA at the transcript level [34], however, PUMA was slightly decreased by SubAB 
treatment (Fig. 2) and p53 level was not increased (data not shown), suggesting that increased PUMA expression by p53 was not the cause of SubAB-induced apoptosis.

JNK plays a critical role in intrinsic apoptotic pathways. It activates apoptotic signaling by upregulation of pro-apoptotic genes through the activation of specific transcription factors or by directly modulating the activities of mitochondrial pro- and anti-apoptotic proteins through phosphorylation (e. g., Bim, Bmf, Bcl-2) $[15,18]$. Other studies show that in ER stress, JNK activation, coupled with Ire1 $\alpha$-TRAF2-ASK1 signaling, induced apoptotic cell death $[35,36]$. SubAB treatment of HeLa cells induced rapid phosphorylation of JNK at around $90 \mathrm{~min}$ and continuing for up to $4 \mathrm{~h}$, with subsequent decrease (Fig. 6B and 9B) similar to previous report [10]. We found that JNK level was decreased by SubAB (Fig. 6B). In contrast, SubAB significantly increased Ire $1 \alpha$ level after $6 \mathrm{~h}$ and Ire $1 \alpha$ was activated by phosphorylation, which was detected by slower migration by SDS-PAGE (Fig. 6C). Phosphorylation was found after $\sim 3$ $\mathrm{h}$ and continued up to $30 \mathrm{~h}$. We asked whether Ire1 $\alpha$ knockdown would suppress JNK activation and apoptosis. Even in cells in which Ire $1 \alpha$ transcript level was almost completely knocked down, however, JNK phosphorylation was not suppressed (Fig. 8A). It seems that JNK activation was not a downstream event following Ire $1 \alpha$ activation. Knockdown of Ire $1 \alpha$ did not inhibit, rather it significantly increased cytochrome $c$ release, caspase-3 activation and PARP cleavage, indicating that this SubAB-induced apoptotic signal pathway did not follow a pathway involving ER stress sensor Ire $1 \alpha$ activation (Fig. 8B). Ire1 $\alpha$ signaling might enhance cell survival. Next, we investigated the effect of gene silencing of JNK1 (Fig. 9). In cells in which JNK1 level was decreased (Fig. 9A), SubAB-induced phosphorylation of JNK1 was suppressed (Fig. 9B), however, cytochrome $c$ release and caspase-3 activation were increased (Fig. 9C). These data suggested that JNK signaling pathway following treatment with SubAB was an anti-apoptotic signal. A role of JNK activation in pro- and anti-apoptotic functions depends on cell type, nature of the death stimulus [15]. A recent study revealed that JNK can suppress apoptosis via phosphorylation of the proapoptotic Bcl-2 family protein, Bad [37]. Since SubAB did not increase Bad phosphorylation (Fig. 2), anti-apoptotic function of JNK by SubAB may not be caused by Bad phosphorylation, We tried to confirm this anti-apoptotic effect of JNK by investigating whether overexpression of JNK protected cells from SubAB-induced apoptosis however, following a $\sim 2$ fold increase of JNK, no difference in cytochrome $c$ release was found (data not shown).

SubAB treatment induces prolonged ER stress detected by continuous BiP cleavage. In SubAB-treated cells, stress sensor Ire1 $\alpha$ expression was significantly increased and activated 
from $3 \mathrm{~h}$ up to $30 \mathrm{~h}$ (Fig. 6C). In contrast, PERK signaling was induced very quickly, as shown in Vero cells by eIF $2 \alpha$ phosphorylation, and attenuated at $3 \mathrm{~h}$ [8]. Similarly, in HeLa cells, eIF2 $\alpha$ phosphorylation was detected only for short periods (data not shown). Signaling through Ire $1 \alpha$ and PERK by SubAB are opposite from the data reported in [38]. In their case, Ire1 $\alpha$ signaling was attenuated during prolonged ER stress and in contrast, ATF6 and PERK signaling persisted. They suggested that Ire $1 \alpha$ attenuation with CHOP activation causes cell death. In our case, prolonged Ire1 $\alpha$ activation as well as continuous CHOP activation were detected. However, CHOP knockdown did not significantly change mitochondrial membrane damage and Ire $1 \alpha$ knockdown increased apoptotic signals, suggesting that Ire1 $\alpha$ or CHOP may inhibit cell death following SubAB treatment.

In this paper, we demonstrated that SubAB-induced cytochrome $c$ release was mainly regulated by Bax and Bak. Those proteins might have a redundant function involved in the regulation of SubAB-induced apoptosis, because only in cells where both genes were knocked down was apoptosis suppressed. SubAB induced conformational changes of Bax and Bak, with complex formation perhaps leading to stable pores, which promote cytochrome $c$ release [30]. It appears that complex formation is not always necessary to induce cytochrome $c$ release, because knockdown of one gene did not decrease cytochrome $c$ release. There are also similar reports that both genes knockdown are necessary to suppress cytochrome $c$ release [39]. The activation pathway for Bax and Bak has not been determined. In mouse cells, ER stress can trigger cellular apoptosis through the activation of caspase-12, which resides on the outside of ER membrane, and is cleaved and activated during ER stress [14]. In human cells, caspase-12 is not expressed; existence of alternative proteins in the ER membrane would be expected.

SubAB-induced cytotoxic effects can be summarized as follows. SubAB is bound to sensitive cells (e.g., Vero cells, HeLa cells), internalized by endocytosis, and transported from the Golgi apparatus to ER in a retrograde manner. The pathway is illustrated in Fig. 10. In the ER lumen, SubAB cleaves BiP, leading to ER stress. SubAB-induced ER stress signals (e.g., Ire1 $\alpha$, CHOP, JNK1) are not involved in cytochrome $c$ release, and might rather promote cell survival. ER stress signals are transferred to Bax/Bak leading to a Bax-Bak complex or maybe mono oligomers of Bax or Bak and cytochrome $c$ release, which activates caspase-3, leading to cell damage in a caspase-dependent way.

\section{Materials and Methods}

\subsection{Cells and reagents}


$\mathrm{HeLa}$ cells were cultured at $37^{\circ} \mathrm{C}$ in a humidified $5 \% \mathrm{CO}_{2}$ atmosphere in Eagle's Minimum Essential Medium (EMEM) containing 10\% heat-inactivated fetal bovine serum, $100 \mathrm{U} / \mathrm{ml}$ penicillin and $0.1 \mathrm{mg} / \mathrm{ml}$ streptomycin. General caspase inhibitor (Z-VAD-FMK) was obtained from BD Biosciences Pharmingen, caspase-8 inhibitor (Z-IETD-FMK) and caspase-9 inhibitor (Z-LEHD-FMK) from R\&D Systems, and caspase-3 inhibitor (Z-DQMD-FMK) from Calbiochem. Cyclosporine A was obtained from Wako Pure Chemical. Primary antibodies were anti-cytochrome $c$ (sc-13560), anti-GAPDH (sc-25778) and anti-CHOP/GADD 153(B-3)(sc-7351) (Santa Cruz Biotechnology); anti-caspases-3 (9662), -9 (9502), and -8(9746), anti-cleaved capases-3 (9661) and -9 (9501), anti-PARP (9542) and -cleaved PARP (9541), anti-Bax (2772), anti-Bak (3814S), anti-Bcl-2 (2870), anti-Bcl-XL (2764), anti-Mcl-1(4572), anti-Bad (9292), anti-p-Bad (9296), anti-Bim (2819), anti-Puma (4976) and anti-Ire1 $\alpha$ (3294S) (Cell Signaling); anti-JNK1(633101) (BioLegend); anti-Bax (clone 3) (610982), anti-BiP (610978) and anti-p-JNK (612540) (BD Biosciences); anti-p53 (Ab-6) (OP-43-100UG) (Oncogene); anti-Bak (Ab-2) (AM04) (Calbiochem). siRNA for Bim, Bax, Bak, CHOP/GADD153, and negative controls were from Santa Cruz Biotechnology. siRNA for JNK1 was from Invitrogen, and that for Ire1 $\alpha$ was from Qiagen.

\subsection{Preparation of SubAB and SubAB(S272A)}

Recombinant His-tagged SubAB and the catalytically inactive mutant, SubAB(S272A), were purified by Ni-NTR chromatography as previously reported [6].

\subsection{Detection of cytochrome $\mathrm{c}$ release from mitochondria}

To evaluate cytochrome $c$ release from mitochondria into cytosol, cells were treated with SubAB $(100 \mathrm{ng} / \mathrm{ml})$ for indicated times, collected with a cell scraper and homogenized for 5 min in buffer ( $75 \mathrm{mM} \mathrm{KCl}, 1 \mathrm{mM} \mathrm{Na} 2 \mathrm{PO}_{4}, 8 \mathrm{mM} \mathrm{Na} 2 \mathrm{HPO}_{4}, 250 \mathrm{mM}$ sucrose, $1 \mathrm{mM}$ EDTA) containing $50 \mu \mathrm{g} / \mathrm{ml}$ digitonin and protease inhibitor cocktail (Roche Diagnostics). Following centrifugation at 10, $000 \mathrm{x} \mathrm{g}$ for $10 \mathrm{~min}$, the supernatant was collected as cytosolic fraction and cytochrome $c$ was detected by Western blotting.

\subsection{Gene silencing in HeLa cells}

HeLa cells ( $1 \times 10^{5}$ cells) in a 12 well-plate were cultured overnight (50-60\% confluent) and were transfected with 10 30 pmol negative control (NC) siRNA or siRNA for Bax, Bak, Bim, JNK1, CHOP, or Ire1 $\alpha$ in Lipofectamine 2000 or Lipofectamine RNAiMAX (Invitrogen) transfection reagent for $48 \mathrm{~h}$ following the company's instructions. Transfection efficiency and effect were evaluated by Western blotting using each antibody.

\subsection{Western blotting analysis}


Cells were plated in a 12 -well dish at $3 \times 10^{5}$ per well one day prior to treatment. After treatment, cells were washed with PBS, lysed with SDS-sample buffer [0.0625M Tris, (pH 6.8), $1 \%$ SDS, $10 \%$ glycerol, $2.5 \%$ mercaptoethanol, $0.001 \%$ bromophenol blue] and heated at $100^{\circ} \mathrm{C}$ for 5 min before proteins were analyzed by SDS-PAGE. After electrophoresis at room temperature, separated proteins were transferred onto PVDF membranes at $100 \mathrm{~V}$ for $1 \mathrm{~h}$. Membranes were blocked with $5 \%$ non-fat milk in TTBS (20 mM Tris (pH 7.6), $137 \mathrm{mM} \mathrm{NaCl}, 0.1 \%$ Tween 20) for $30 \mathrm{~min}$ and then incubated with primary antibodies for $1 \mathrm{~h}$ at room temperature or sometimes overnight at $4^{\circ} \mathrm{C}$. After washing the membranes three times for $5 \mathrm{~min}$ with TTBS, the membranes were incubated with horseradish peroxidase-labeled secondary antibodies for 1 $\mathrm{h}$ at room temperature. Bands were visualized using Las 1000 (Fuji film). To investigate the effect of caspase inhibitors, cells were treated with inhibitors for $30 \mathrm{~min}$ prior to treatment with toxin and then incubated for $30 \mathrm{~h}$ with SubAB.

\subsection{Intracellular flow cytometric analysis}

Assay was performed by the method of Dewton et al. [28]. Briefly, cells were fixed with $2 \%$ formaldehyde for $10 \mathrm{~min}$ at room temperature, then washed in PBS and incubated for $45 \mathrm{~min}$ on ice in the presence of anti-Bax clone 3 monoclonal antibody $(1 \mu \mathrm{g} / \mathrm{ml})$ diluted in permeabilization buffer (1.25\% BSA, 0.1\% saponin in PBS). As a negative control cells were incubated in the absence of primary antibody. Cells were washed with $0.5 \%$ BSA/PBS and incubated with Alexa 488 conjugated secondary antibody (1:100). Cells were washed with $0.5 \%$ BSA/PBS, resuspended in PBS and analyzed by FACSCantoII.

\subsection{Construct of Mcl-1 expression plasmid and transfection}

Total RNA was extracted from HeLa cells using RNeasy Mini Kit (Qiagen) according to the manufacturer's instructions. Complementary DNA (cDNA) was synthesized from $5 \mu \mathrm{g}$ of total RNA using Ready-To-Go You-Prime First-Strand Beads (GE Healthcare). Primers used for Mcl-1 amplification were 5' - caccatgtttggectcaaaagaaacgcggt-3' and 5'-tcttattagatatgccaaaccagctcctac-3'. cDNA was amplified in $50 \mu \mathrm{l}$ of PrimeSTAR ${ }^{\text {TM }}$ GC PCR mixture according to the manufacturer's protocol (TaKaRa Bio). The PCR conditions were as follows: 30 cycles of $98{ }^{\circ} \mathrm{C}$ for $10 \mathrm{~s}$ and $68^{\circ} \mathrm{C}$ for $90 \mathrm{~s}$. To add $3^{\prime}$ adenine-overhangs, ExTaq polymerase $\left(0.5 \mu \mathrm{l}\right.$, TaKaRa Bio) was incubated with the reaction mixture at $72{ }^{\circ} \mathrm{C}$ for $10 \mathrm{~min}$. PCR products were subjected to electrophoresis on $1 \%$ agarose gels containing ethidium bromide, and the band was extracted by Gel Extraction Kit (Qiagen) and then inserted in the cloning site of pcDNA3.2/V5/GW/D-TOPO vector (Invitrogen). The Mcl-1 gene was confirmed by sequencing. Cells were cultured in a 12 well dishes $\left(1 \times 10^{5} /\right.$ well $)$ overnight and 
transfected with $1 \mu \mathrm{g}$ of plasmids using lipofectamine LTX and Plus reagent (Invitrogen). After $24 \mathrm{~h}$ incubation, cells were treated with SubAB for $30 \mathrm{~h}$.

\subsection{Immunoprecipitation}

Immunoprecipitation of Bax/Bak complex was carried out as described previously [40]. Briefly, HeLa cells $\left(3 \times 10^{5} / 6 \mathrm{~cm}\right.$ plate) were treated with $\mathrm{SubAB}$, SubAB(S272A) or control PBS for $36 \mathrm{hr}$. After washing with ice-cold PBS, cells were solubilized with lysis buffer (10 mM HEPES, $150 \mathrm{mM} \mathrm{NaCl}, 1.5 \mathrm{mM} \mathrm{MgCl}_{2}, 1 \mathrm{mM}$ EGTA, 2\% CHAPS, pH 7.4) containing protease inhibitor cocktail (Roche Diagnostics) and incubated for $30 \mathrm{~min}$ on ice. After centrifugation at $17,400 \mathrm{x}$ g for $15 \mathrm{~min}$ at $4^{\circ} \mathrm{C}$, solubilized extracts $(150 \mu \mathrm{g} / 200 \mu \mathrm{l})$ were collected and incubated with $0.25 \mu \mathrm{g}$ of normal mouse IgG (Santa Cruz Biotechnology), anti-Bax antibody (clone 3) (BD Bioscience) or anti-Bak antibody (Ab-2) (Calbiochem) at $4{ }^{\circ} \mathrm{C}$ for $2 \mathrm{hr}$. Immunoprecipitates were collected by incubation with protein G-Sepharose (Invitrogen) for $1 \mathrm{~h}$, followed by centrifugation for $1 \mathrm{~min}$ at $4{ }^{\circ} \mathrm{C}$. After immunocomplexes were washed with lysis buffer three times, proteins were dissolved in SDS-sample buffer, applied to SDS-PAGE in $15 \%$ gels, transferred to PVDF membranes, and then analyzed by Western blotting using anti-Bax or anti-Bak antibodies (Cell Signaling)

\subsection{Cytotoxicity}

Cytotoxicity Detection Kit ${ }^{\text {PLUS }}[\mathrm{LDH}]$ (Roche Diagnostics) was used to evaluate the cell cytotoxicity according to manufacturer's instructions. Briefly, cells were treated with or without SubAB (200 $\mathrm{ng} / \mathrm{ml})$ for the indicated time and then assayed for LDH release in culture medium. To determine the percentage cytotoxicity, the average absorbance values of the triplicate samples and controls were calculated. Cell cytotoxicity was calculated from the values using the following formula: cell cytotoxicity $(\%$ of control $)=($ the absorbance values of SubAB-treated cells minus the absorbance values of untreated cells)/(the absorbance values of high control by cell lysis solution treatment minus the absorbance values of untreated cells) $\mathrm{x} 100$.

\subsection{Apoptosis}

To define the apoptotic cells, we used Cell Death Detection ELISA ${ }^{\text {PLUS }}$ ELISA kit (Roche Diagnostics) as described in the manufacturer's instructions. Briefly, cells were treated with SubAB (200 ng/ml), SubAB(S272A) or control PBS for indicated times and lysed with $200 \mu \mathrm{l}$ of cell lysis buffer. Lysates from floating and adherent cells were added to a streptavidin coated microplate and incubated with a mixture of anti-histone-biotin and anti-DNA peroxidase. After washing the plate with incubation buffer, peroxidase substrates (ABTS) were added to each 
well and absorbance was measured at $405 \mathrm{~nm}$. The enrichment factor quantified the specific enrichment of mono- and oligonucleosomes released into the cytoplasm and was calculated using the following formula: enrichment factor $=$ (the absorbance of dying $/$ dead cells $) /$ the absorbance of control cells).

\section{Acknowledgement}

This work was supported by Grants-in Aid for Scientific Research from Japan Society for the Promotion of Science and for Improvement of Research Environment for Young Researchers from Japan Science and Technology Agency. Joel Moss was supported by the Intramural Research Program, National Institute of Health, National Heart, Lung and Blood Institute. We thank Dr. Iwao Kato, the former professor of Chiba University, for useful discussions and critical review of the manuscript. We thank Dr. Eisuke Nishida and Dr. Hiroyuki Seimia for providing JNK expression vector.

Abbreviations used are: PTP, mitochondrial permeability transition pore; JNK, cJun N-terminal kinase; CHOP, C/EBF-homologue protein; ER, endoplasmic reticulum; HUS, hemolytic uremic syndrome; PERK, double-stranded RNA-activated protein kinase-like ER kinase; eIF2 $\alpha$, eukaryotic initiation factor-2 $\alpha$; EMEM, Eagle's Minimum Essential Medium; OMM, mitochondria outer membrane.

\section{Legends to Figures}

Fig. 1. Effects of SubAB in HeLa cells.

A. SubAB-induced caspase activation in HeLa cells. Cells were incubated with $100 \mathrm{ng} / \mathrm{ml}$ of SubAB for $30 \mathrm{~h}$, and then detached from the substratum with cell scraper, collected by centrifugation, washed once with PBS, and then lysed with $100 \mu \mathrm{l}$ of SDS-sample buffer. Western blotting was performed as described in Materials and Methods. B. Cells were incubated with $100 \mathrm{ng} / \mathrm{ml}$ of SubAB or SubAB(S272A) for indicated times, and then washed once with PBS, and then lysed with $100 \mu \mathrm{l}$ of SDS-sample buffer. Western blotting was 
performed as described in Materials and Methods. C. Cells were incubated with various caspase inhibitors $(50 \mu \mathrm{M})$ for $30 \mathrm{~min}$, followed by incubation with SubAB for $30 \mathrm{~h}$. Cytochrome $c$ release into the cytoplasmic fraction was determined as described in Materials and Methods. The data shown are representative of three separate experiments. 1; control without inhibitor 2; general caspase inhibitor, 3; caspase-3 inhibitor, 4; caspase-8 inhibitor, 5; caspase-9 inhibitor, 6; control without inhibitor.

Fig. 2. Effects of SubAB on expression of Bcl-2 family proteins.

Cells were plated in a 12 -well dish at $3 \times 10^{5}$ per well one day prior to incubation with SubAB or catalytically inactive $\operatorname{SubAB}(\mathrm{S} 272 \mathrm{~A})(200 \mathrm{ng} / \mathrm{ml})$ for indicated times. Cells were then detached from the substratum with cell scraper, collected by centrifugation, washed once with PBS, and then lysed with $100 \mu \mathrm{l}$ of SDS-sample buffer. Western blotting was performed as described in Materials and Methods. An upper arrow indicates phosphorylated Bim. Experiments were performed three times; a representative blot is shown.

Fig. 3. Effect of cyclosporine A on SubAB-induced cytochrome $c$ release.

Cells were grown overnight, and then cyclosporine A was added at the indicated concentration for $30 \mathrm{~min}$ before addition of SubAB (100 ng/ml) and incubation for $30 \mathrm{~h}$. Cytochrome $c$ and caspase- 3 were quantified by Western blotting. Data are representative of three experiments.

Fig. 4. SubAB-induced Bax activation in HeLa cells. A. FACS analysis of SubAB-induced Bax conformational change. Cells were grown overnight and then incubated with or without SubAB $(200 \mathrm{ng} / \mathrm{ml})$ for indicated times. Intracellular flow cytometric analysis was performed as described in Materials and Methods. Control: without first antibody (Bax, clone 3). Graph shows $\%$ of conformationally changed Bax (subtracted the amount of control). Data shown are representative of three experiments. B. Conformational changes and association of Bax and Bak. Cells were treated with $200 \mathrm{ng} / \mathrm{ml}$ of SubAB, SubAB(S272A), or no toxin for $30 \mathrm{~h}$ and then cells were lysed and immunoprecipitated with conformation-specific Bax or Bak antibody as described in Materials and Methods. Left panel shows the total lysate and right panel shows the Bax and Bak, which were immunoprecipitated by conformation-specific anti-Bax or -Bak antibody. 
Fig. 5. Effect of Bax or Bak silencing on SubAB-induced cytochrome $c$ release from mitochondria.

A. Cells were grown overnight, and silencing of bax or bak alone or both bax and bak gene was performed with Bax-, Bak-, or NC-siRNA as described in Materials and Methods. Forty-eight h after transfection, cells were incubated with SubAB $(200 \mathrm{ng} / \mathrm{ml})$ for $30 \mathrm{~h}$ or $34 \mathrm{~h}$. SubAB-treated cells were analyzed by Western blotting with antibodies against cytochrome $c$ or caspase-3. Cytochrome $c$ release was determined as described in Materials and Methods. The blots shown are representative of three other experiments. Right panel shows the densitometric analysis of cytochrome $c$ release and caspase-3. Data are the means \pm SD value from three separate experiments. $* \mathrm{p}<0.07, * * \mathrm{p}<0.05$. B. DNA fragmentation of SubAB-treated cells was analyzed as described in Materials and Methods. Data are the means \pm SD value from three separate experiments. C. Cytotoxicity of SubAB-treated cells was analyzed as described in Materials and Methods. Data are the means \pm SD value from three separate experiments.

Fig. 6. Changes of expression levels of CHOP (A), JNK1 or p-JNK (B) and Ire1 $\alpha$ (C) by incubation with SubAB.

Cells were grown overnight, and then incubated with SubAB $(200 \mathrm{ng} / \mathrm{ml})$ for indicated times. After incubation, cells were scraped from the plate, washed once with PBS, solubilized with 1x SDS sample buffer and then heated for $5 \mathrm{~min}$. Samples were analyzed by Western blotting as described in Materials and Methods. Blots shown are representative of at least three experiments.

Fig. 7. Effect of CHOP silencing on SubAB-induced cytochrome $c$ release from mitochondria in HeLa cells. Experiments were performed similar to those in the legend to Supplementary Figure S2. A. After transfection of CHOP- or NC-siRNA for $48 \mathrm{~h}$, cells were incubated with SubAB for $30 \mathrm{~h}$ and induction of CHOP was quantified by Western blotting. B. Transfected cells were incubated with SubAB for 30 or $34 \mathrm{~h}$ and cytochrome $c$ release into the cytoplasmic fraction was determined as described in Materials and Methods. Blots shown are representative of three experiments. Quantification of cytochrome $c$ was performed by densitometer (lower panel). Data are the means \pm SD value from three separate experiments. 
Fig. 8. Effect of Ire $1 \alpha$ silencing on SubAB-induced cytochrome $c$ release from mitochondria. Ire $1 \alpha$ silencing was performed as described in Materials and Methods. A. Cells transfected with Ire $1 \alpha-$ or NC-siRNA were incubated with SubAB $(200 \mathrm{ng} / \mathrm{ml})$ for indicated times and then analyzed by Western blotting with antibodies against Ire1 $\alpha, \mathrm{p}-\mathrm{JNK}$, or GAPDH. A blot representative of three other experiments is shown. B. Cells transfected with Ire $1 \alpha-$ or NC-siRNA were incubated with SubAB $(200 \mathrm{ng} / \mathrm{ml})$ for $30 \mathrm{~h}$ and then samples for Western blotting were prepared. Blots were analyzed with antibodies against caspase-3, cytochrome $c$, cleaved PARP and GAPDH. The blots shown are representative of three other experiments.

Fig. 9. Effect of JNK silencing on SubAB-induced cytochrome $c$ release from mitochondria. JNK1 silencing was performed as described in Materials and Methods. A. Reduction of JNK1 protein level was confirmed by Western blotting with anti-JNK antibodies. B. Cells transfected with NC- or JNK1-siRNA were incubated with SubAB (200 ng/ml) for indicated times and then cells were analyzed by Western blotting with antibodies reactive with p-JNK. C. Cells transfected with NC- or JNK1-siRNA were incubated with SubAB (200 ng/ml) for 30 or $34 \mathrm{~h}$ and then samples for Western blotting were prepared. Blots were analyzed with antibodies reactive with caspase-3, cytochrome $c$ and GAPDH. The blots shown are representative of three other experiments. Quantification of cytochrome $c$ was performed by densitometer (right panel). Data are the means \pm SD value from three separate experiments. ${ }^{*}, \mathrm{p}<0.02,{ }^{*} \mathrm{p}<0.07$.

Fig. 10. Proposed pathway of SubAB-induced apoptosis. See text for additional details.

Supplemental information

Figure legends

Figure S1. Effect of overexpression of Mcl-1 on SubAB-induced cytochrome $c$ release.

Cells $\left(1 \times 10^{5}\right.$ cells/well) in 12 well plates were grown overnight and transfected with $1 \mu \mathrm{g}$ of vector plasmid or V5-tagged Mcl-1 cDNA expression plasmid using lipofectamine LTX and Plus reagent. After incubation for $24 \mathrm{~h}$, cells were treated with or without SubAB (200 ng/ml) 
for $30 \mathrm{~h}$, and cytochrome $c$ or caspase-3 was detected by Western blotting. Right panel shows quantification of cytochrome $c$ released by densitometer. Data are the means \pm SD value from three separate experiments.

Figure S2. Effect of Bim or Bax silencing on SubAB-induced cytochrome $c$ release.

Cells were grown overnight, and silencing of bax or bim gene was performed with Bax- or Bim-siRNA or NC-siRNA as described in Materials and Methods. Forty-eight $\mathrm{h}$ after transfection, cells were incubated with SubAB (200 ng/ml) for $30 \mathrm{~h}$. A. Reduction of Bax or Bim protein level was confirmed by Western blotting with anti-Bax or Bim antibodies. Right panel shows quantification of Bax or Bim by densitometer. Data are the means \pm SD value from three separate experiments. B. Cytochrome $c$ release into the cytoplasmic fraction was determined as described in Materials and Methods. A blot representative of three other experiments is shown. Right panel shows quantification of cytochrome $c$ by densitometer. Data are the means \pm SD value from three separate experiments.

Figure S3. Reduction of Bax or Bak protein level in Fig. 5.

Reduction of Bax or Bak protein level was confirmed by Western blotting with anti-Bax or anti-Bak antibodies. Quantification of Bax or Bak was performed by densitometer. Data are the means \pm SD value from three separate experiments.

References

1. Paton, A.W., et al., A new family of potent $A B(5)$ cytotoxins produced by Shiga toxigenic Escherichia coli. J Exp Med, 2004. 200(1): p. 35-46.

2. Paton, A.W., et al., AB5 subtilase cytotoxin inactivates the endoplasmic reticulum chaperone BiP. Nature, 2006. 443(7111): p. 548-52.

3. Yahiro, K., et al., Identification and characterization of receptors for vacuolating activity of subtilase cytotoxin. Mol Microbiol, 2006. 62(2): p. 480-90.

4. Byres, E., et al., Incorporation of a non-human glycan mediates human susceptibility to 
a bacterial toxin. Nature, 2008. 456(7222): p. 648-52.

5. Wang, H., J.C. Paton, and A.W. Paton, Pathologic changes in mice induced by subtilase cytotoxin, a potent new Escherichia coli AB5 toxin that targets the endoplasmic reticulum. J Infect Dis, 2007. 196(7): p. 1093-101.

6. Morinaga, N., et al., Two distinct cytotoxic activities of subtilase cytotoxin produced by shiga-toxigenic Escherichia coli. Infect Immun, 2007. 75(1): p. 488-96.

7. $\quad$ Hendershot, L.M., The ER function BiP is a master regulator of ER function. Mt Sinai J Med, 2004. 71(5): p. 289-97.

8. Morinaga, N., et al., Subtilase cytotoxin, produced by Shiga-toxigenic Escherichia coli, transiently inhibits protein synthesis of Vero cells via degradation of BiP and induces cell cycle arrest at G1 by downregulation of cyclin D1. Cell Microbiol, 2008. 10(4): p. 921-9.

9. Wolfson, J.J., et al., Subtilase cytotoxin activates PERK, IRE1 and ATF6 endoplasmic reticulum stress-signalling pathways. Cell Microbiol, 2008. 10(9): p. 1775-86.

10. Lass, A., et al., Decreased ER-associated degradation of alpha-TCR induced by Grp78 depletion with the SubAB cytotoxin. Int J Biochem Cell Biol, 2008. 40(12): p. 2865-79.

11. Matsuura, G., et al., Novel subtilase cytotoxin produced by Shiga-toxigenic Escherichia coli induces apoptosis in vero cells via mitochondrial membrane damage. Infect Immun, 2009. 77(7): p. 2919-24.

12. Youle, R.J. and A. Strasser, The BCL-2 protein family: opposing activities that mediate cell death. Nat Rev Mol Cell Biol, 2008. 9(1): p. 47-59.

13. Adams, J.M. and S. Cory, The Bcl-2 apoptotic switch in cancer development and therapy. Oncogene, 2007. 26(9): p. 1324-37.

14. Szegezdi, E., et al., Mediators of endoplasmic reticulum stress-induced apoptosis. EMBO Rep, 2006. 7(9): p. 880-5.

15. Dhanasekaran, D.N. and E.P. Reddy, JNK signaling in apoptosis. Oncogene, 2008. 27(48): p. 6245-51.

16. Akgul, C., Mcl-1 is a potential therapeutic target in multiple types of cancer. Cell Mol Life Sci, 2009. 66(8): p. 1326-36.

17. Willis, S.N., et al., Proapoptotic Bak is sequestered by Mcl-1 and Bcl-xL, but not Bcl-2, until displaced by BH3-only proteins. Genes Dev, 2005. 19(11): p. 1294-305.

18. Putcha, G.V., et al., JNK-mediated BIM phosphorylation potentiates BAX-dependent apoptosis. Neuron, 2003. 38(6): p. 899-914. 
19. Bouillet, P., et al., BH3-only Bcl-2 family member Bim is required for apoptosis of autoreactive thymocytes. Nature, 2002. 415(6874): p. 922-6.

20. Willis, S.N., et al., Apoptosis initiated when BH3 ligands engage multiple Bcl-2 homologs, not Bax or Bak. Science, 2007. 315(5813): p. 856-9.

21. Puthalakath, H., et al., ER stress triggers apoptosis by activating BH3-only protein Bim. Cell, 2007. 129(7): p. 1337-49.

22. Yang, E., et al., Bad, a heterodimeric partner for Bcl-XL and Bcl-2, displaces Bax and promotes cell death. Cell, 1995. 80(2): p. 285-91.

23. Roy, S.S., et al., Bad targets the permeability transition pore independent of Bax or Bak to switch between Ca2+-dependent cell survival and death. Mol Cell, 2009. 33(3): p. $377-88$.

24. Yung, H.W., et al., Endoplasmic reticulum stress exacerbates ischemia-reperfusion-induced apoptosis through attenuation of Akt protein synthesis in human choriocarcinoma cells. FASEB J, 2007. 21(3): p. 872-84.

25. Wang, S.W., et al., CHM-1, a novel synthetic quinolone with potent and selective antimitotic antitumor activity against human hepatocellular carcinoma in vitro and in vivo. Mol Cancer Ther, 2008. 7(2): p. 350-60.

26. Wan, K.F., et al., Chelerythrine induces apoptosis through a Bax/Bak-independent mitochondrial mechanism. J Biol Chem, 2008. 283(13): p. 8423-33.

27. Hsu, Y.T., K.G. Wolter, and R.J. Youle, Cytosol-to-membrane redistribution of Bax and Bcl-X(L) during apoptosis. Proc Natl Acad Sci U S A, 1997. 94(8): p. 3668-72.

28. Dewson, G., et al., Conformational change and mitochondrial translocation of Bax accompany proteasome inhibitor-induced apoptosis of chronic lymphocytic leukemic cells. Oncogene, 2003. 22(17): p. 2643-54.

29. Annis, M.G., et al., Bax forms multispanning monomers that oligomerize to permeabilize membranes during apoptosis. Embo J, 2005. 24(12): p. 2096-103.

30. Zhou, L. and D.C. Chang, Dynamics and structure of the Bax-Bak complex responsible for releasing mitochondrial proteins during apoptosis. J Cell Sci, 2008. 121(Pt 13): p. 2186-96.

31. McCullough, K.D., et al., Gadd153 sensitizes cells to endoplasmic reticulum stress by down-regulating Bcl2 and perturbing the cellular redox state. Mol Cell Biol, 2001. 21(4): p. 1249-59.

32. Gotoh, T., et al., hsp70-DnaJ chaperone pair prevents nitric oxide- and CHOP-induced 
apoptosis by inhibiting translocation of Bax to mitochondria. Cell Death Differ, 2004. 11(4): p. 390-402.

33. Zinszner, H., et al., CHOP is implicated in programmed cell death in response to impaired function of the endoplasmic reticulum. Genes Dev, 1998. 12(7): p. 982-95.

34. Li, J., B. Lee, and A.S. Lee, Endoplasmic reticulum stress-induced apoptosis: multiple pathways and activation of p53-up-regulated modulator of apoptosis (PUMA) and NOXA by p53. J Biol Chem, 2006. 281(11): p. 7260-70.

35. Nishitoh, H., et al., ASK1 is essential for endoplasmic reticulum stress-induced neuronal cell death triggered by expanded polyglutamine repeats. Genes Dev, 2002. 16(11): p. 1345-55.

36. Urano, F., et al., Coupling of stress in the ER to activation of JNK protein kinases by transmembrane protein kinase IREI. Science, 2000. 287(5453): p. 664-6.

37. Yu, C., et al., JNK suppresses apoptosis via phosphorylation of the proapoptotic Bcl-2 family protein BAD. Mol Cell, 2004. 13(3): p. 329-40.

38. Lin, J.H., et al., IRE1 signaling affects cell fate during the unfolded protein response. Science, 2007. 318(5852): p. 944-9.

39. Wei, M.C., et al., Proapoptotic BAX and BAK: a requisite gateway to mitochondrial dysfunction and death. Science, 2001. 292(5517): p. 727-30.

40. Mikhailov, V., et al., Bcl-2 prevents Bax oligomerization in the mitochondrial outer membrane. J Biol Chem, 2001. 276(21): p. 18361-74. 
Fig.1

A
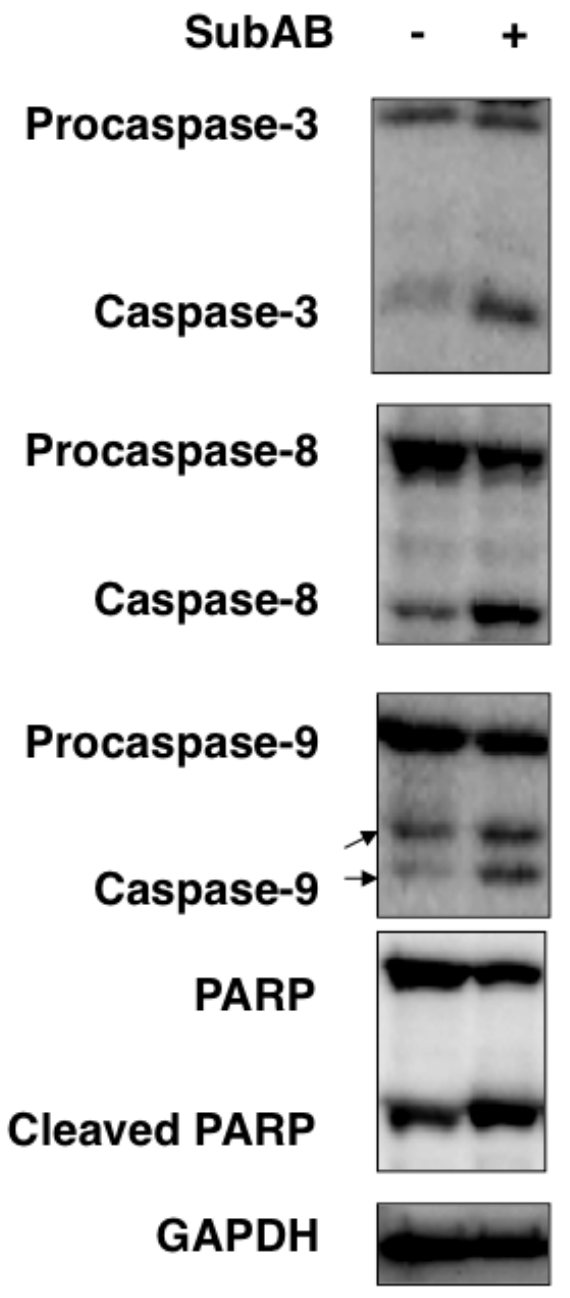

B

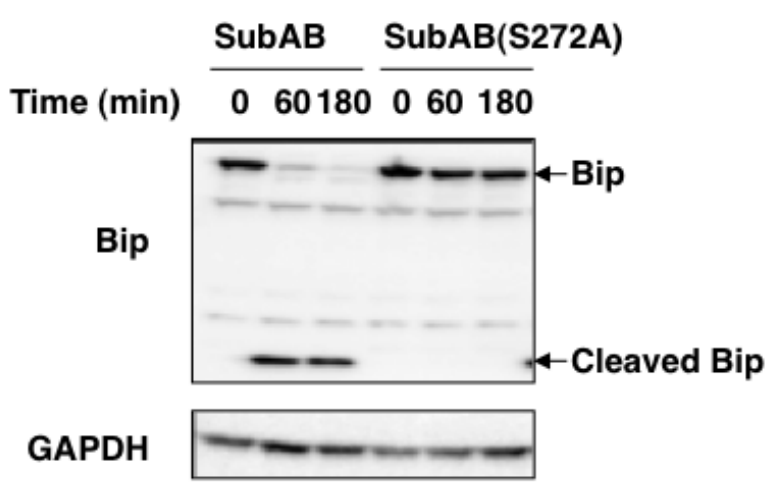

C

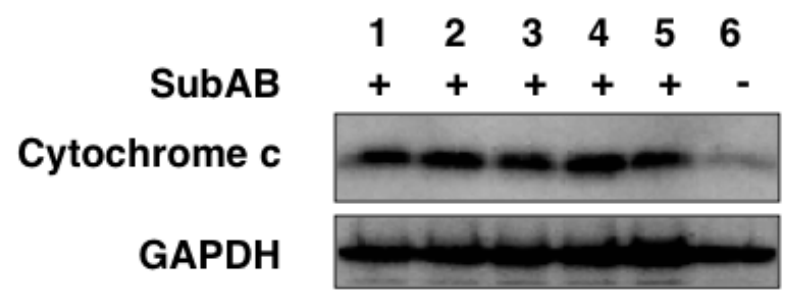


Fig.2

$\begin{array}{llllllll}\text { Time (h) } & 0 & 1 & 2 & 6 & 17 & 24 & 30\end{array}$

Pro-survival group $\left(\begin{array}{c}\text { Bcl-2(26 kDa) } \\ \text { Bcl-XL(31 kDa) } \\ \text { Mcl-1 (40 kDa) }\end{array}\right.$

Pro-apoptotic group

$$
\text { Activator }\left\{\begin{array}{r}
\operatorname{Bad}(23 \mathrm{kDa}) \\
\mathrm{p}-\mathrm{Bad}(23 \mathrm{kDa}) \\
\mathrm{Bim}(23 \mathrm{kDa}) \\
\text { Puma(18,23 kDa) }
\end{array}\right.
$$
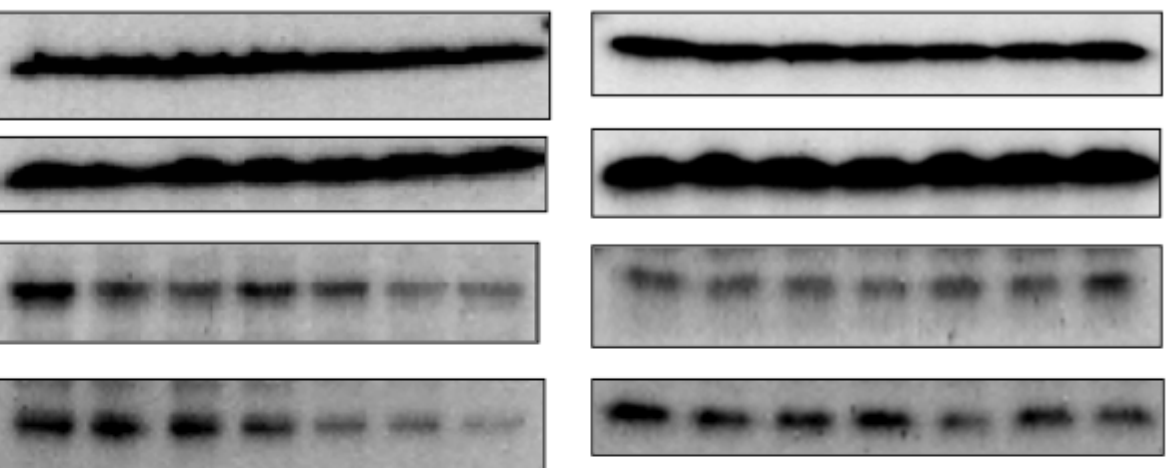
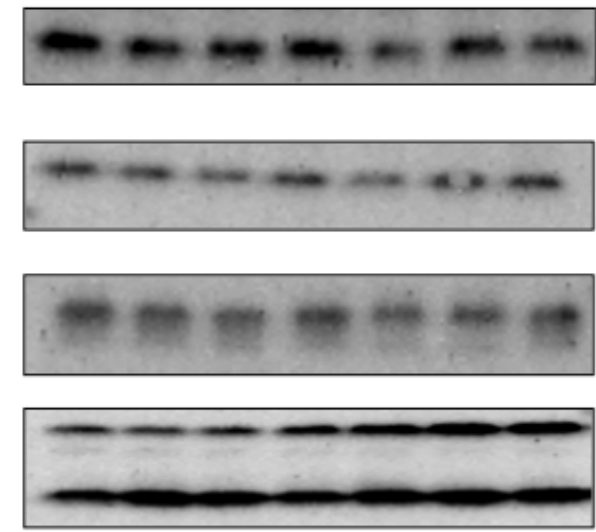

$\begin{array}{lllllll}0 & 1 & 2 & 6 & 17 & 24 & 30\end{array}$
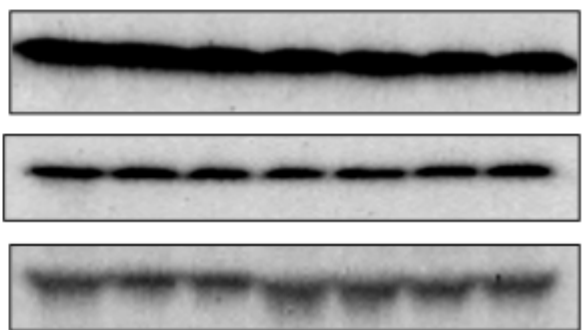
Fig.3

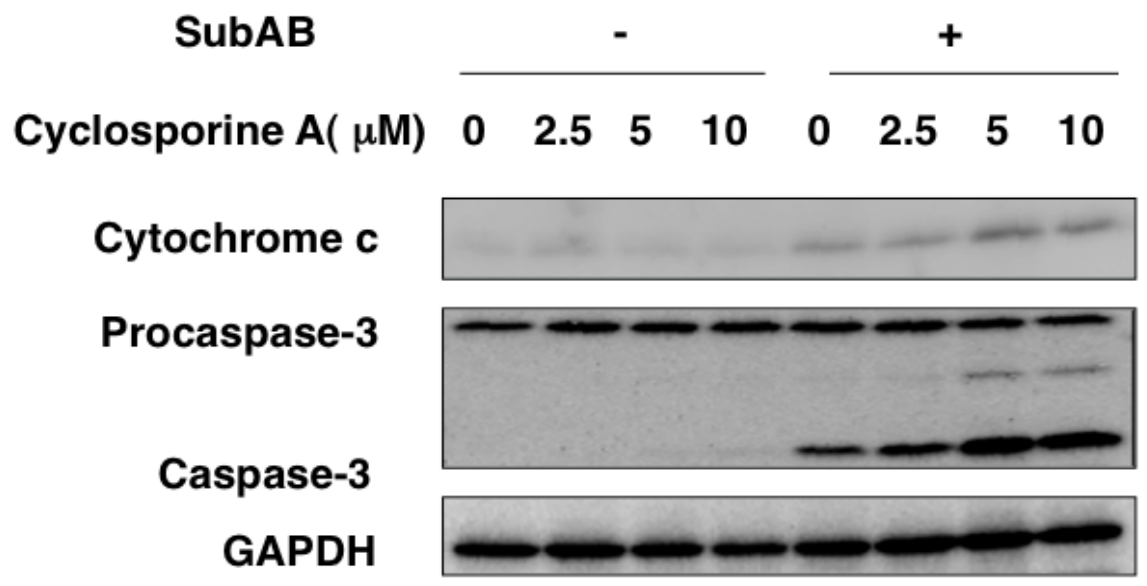


Fig.4A

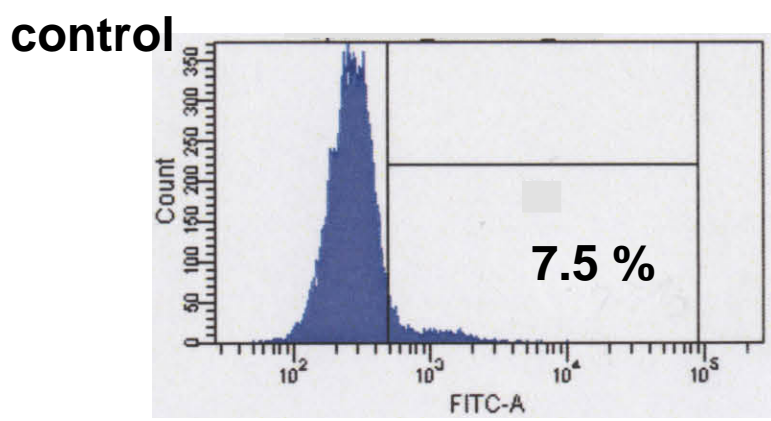

$38 \mathrm{~h}$
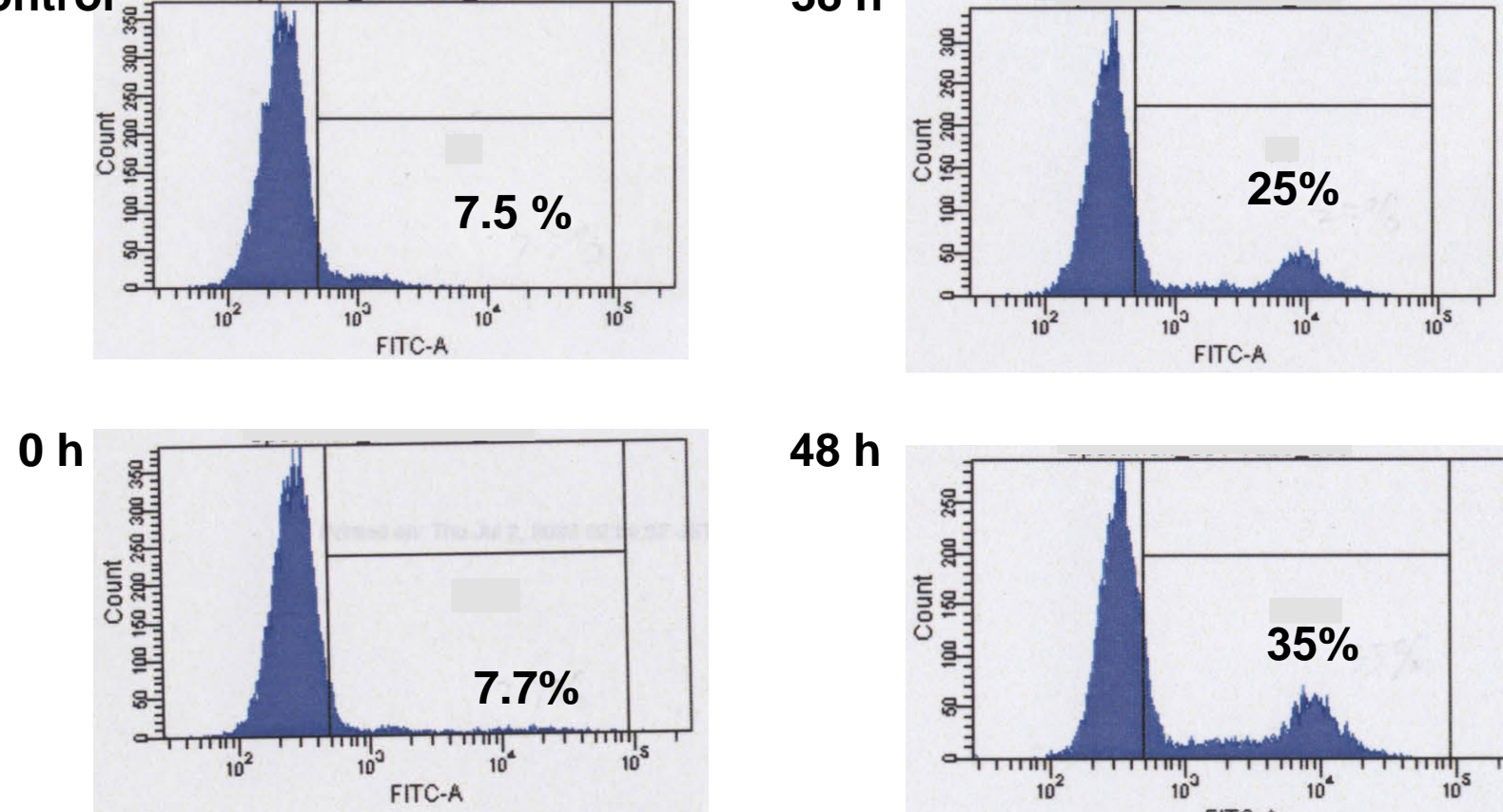

$48 \mathrm{~h}$
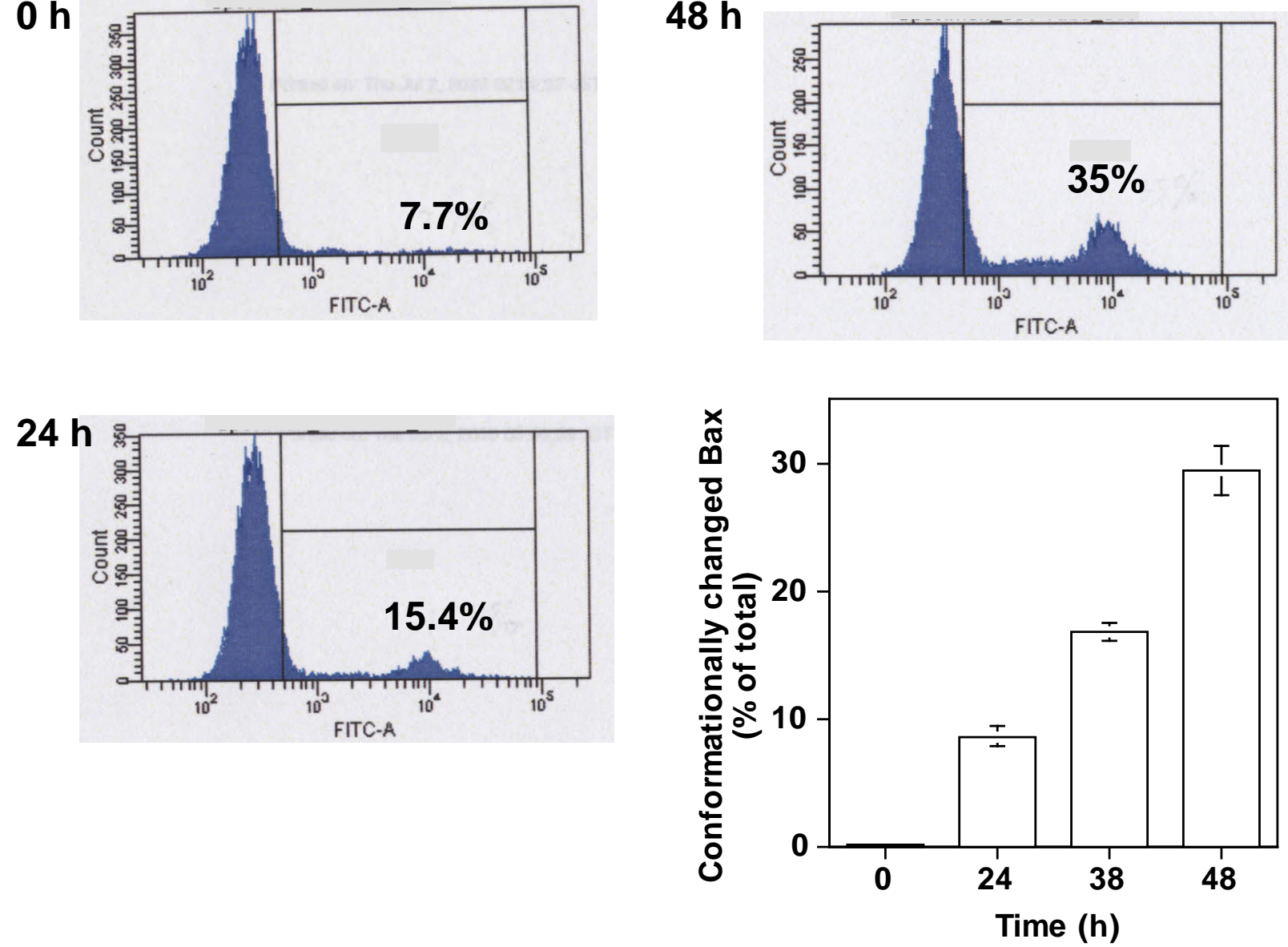
Fig.4B

Total lysate
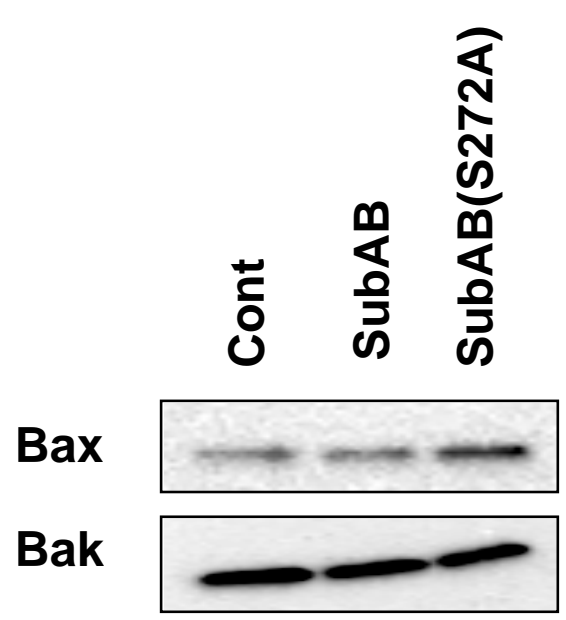

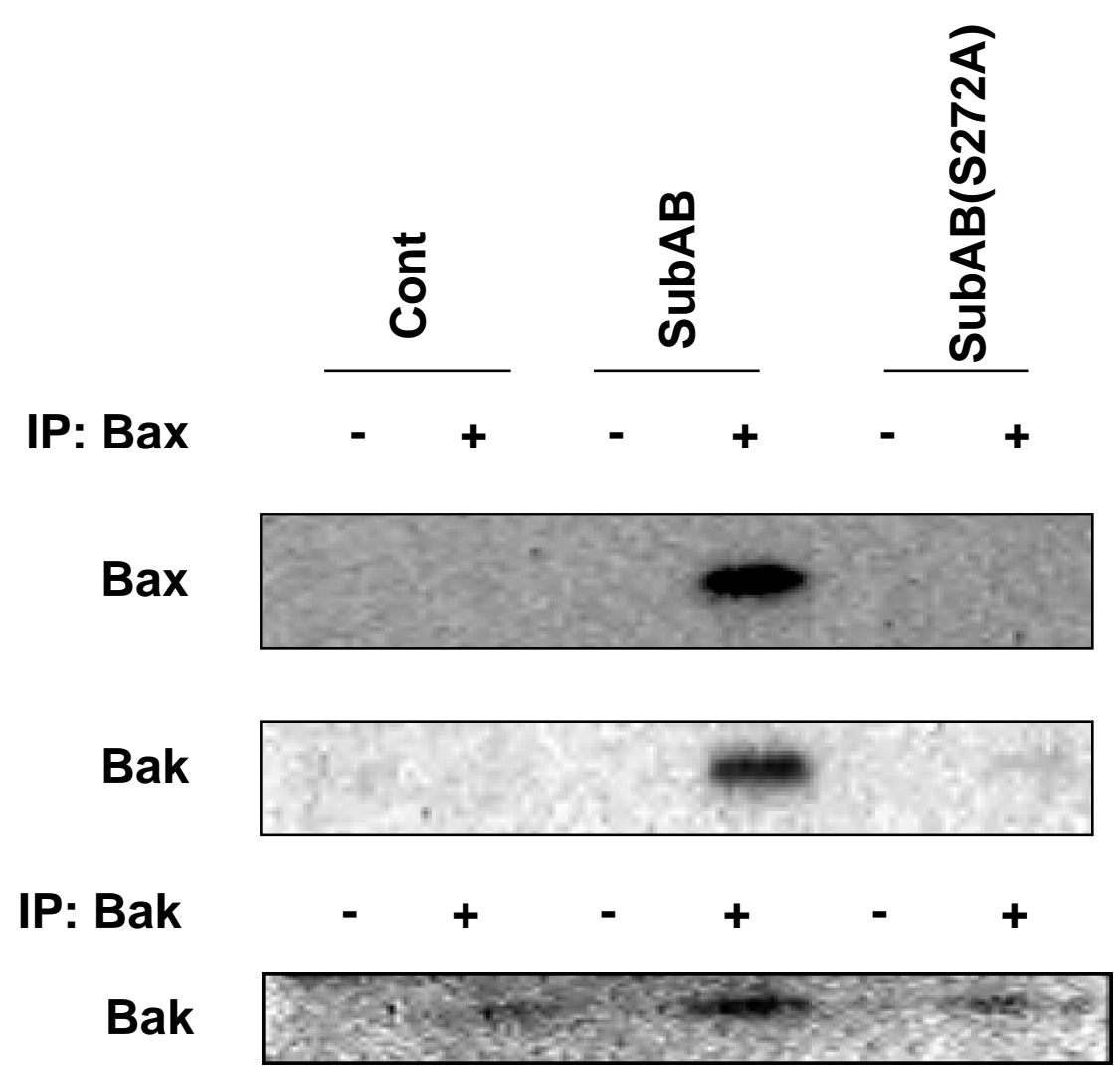


Fig.5

A.

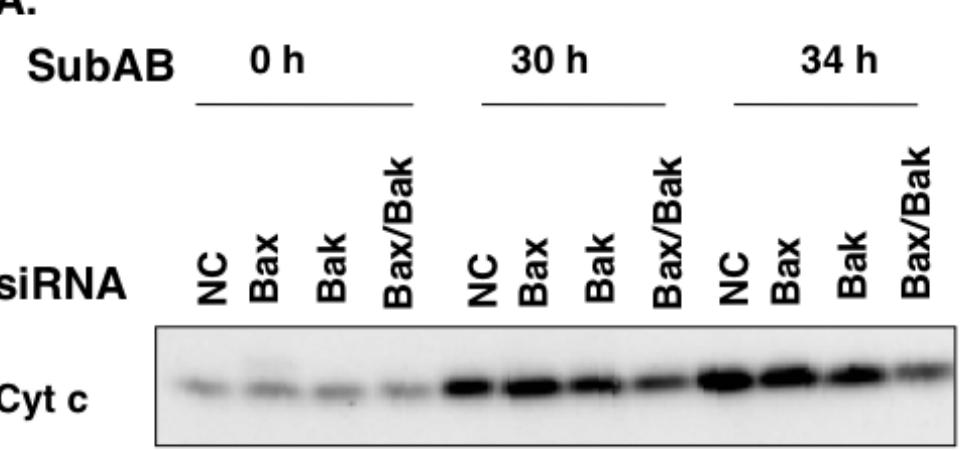

Cas-3
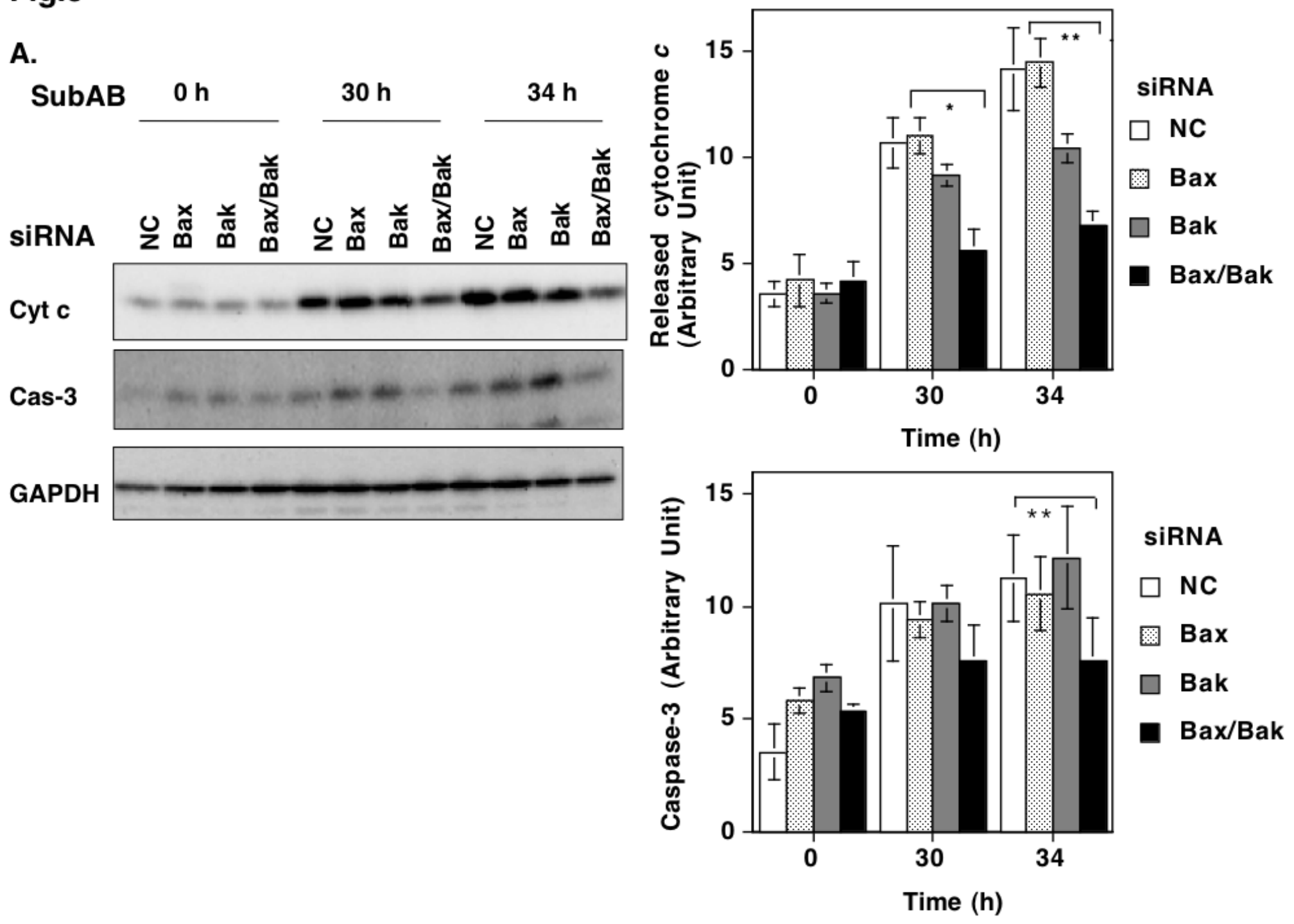
Fig. 5

B

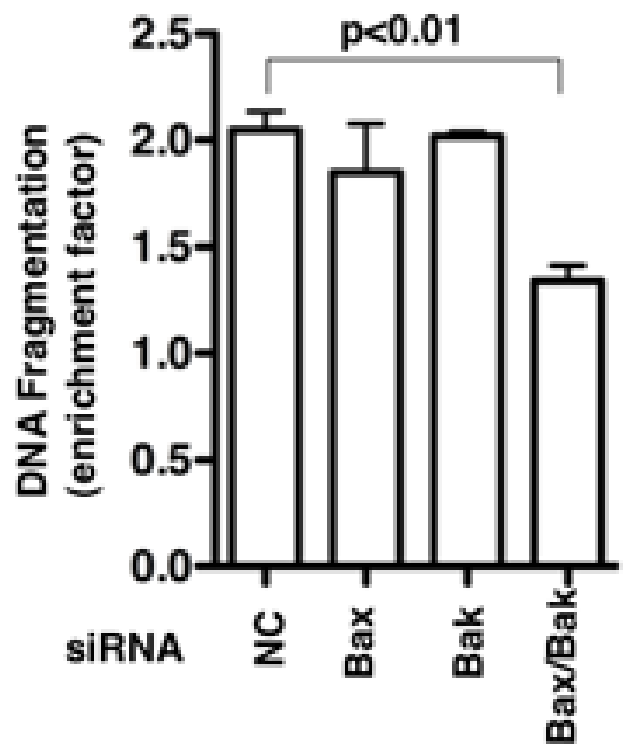

C

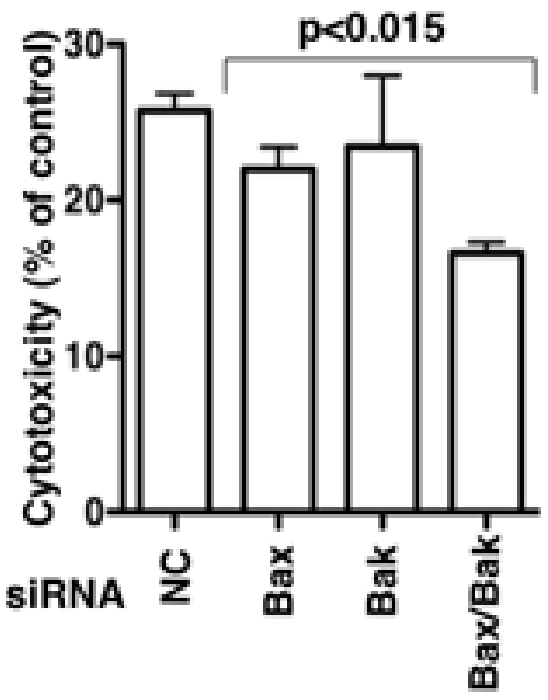


Fig.6

A

$\begin{array}{llllllll}\text { Time (h) } & 0 & 1 & 2 & 6 & 17 & 24 & 30\end{array}$

CHOP

GAPDH
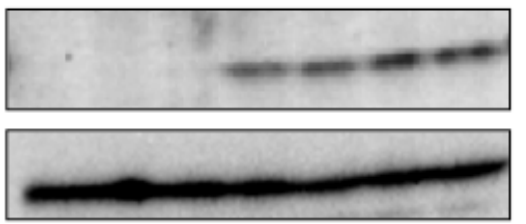

B

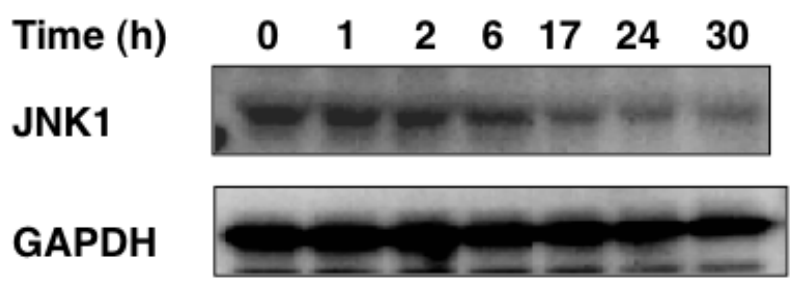

$\begin{array}{lllllllll}\text { Time (h) } & 0 & 1 & 2 & 4 & 6 & 17 & 24 & 30\end{array}$

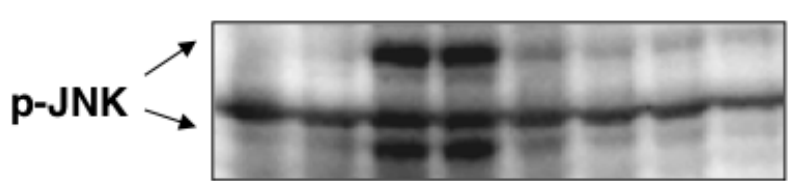

GAPDH
C
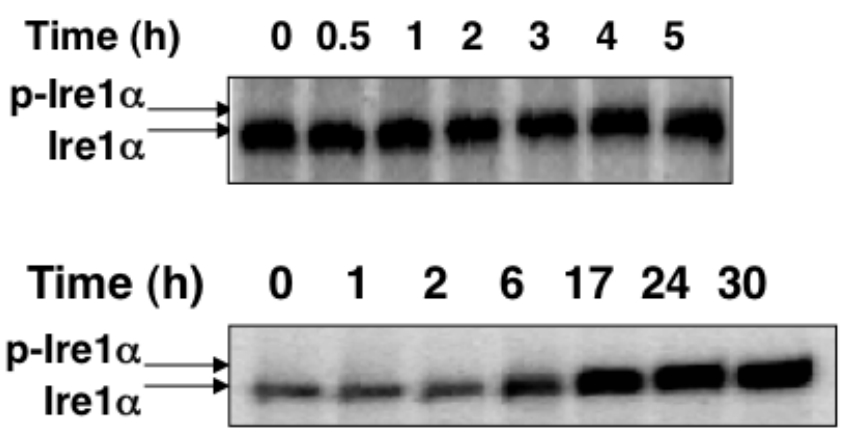
Fig. 7

A

SIRNA CHOP NC

CHOP

GAPDH
B
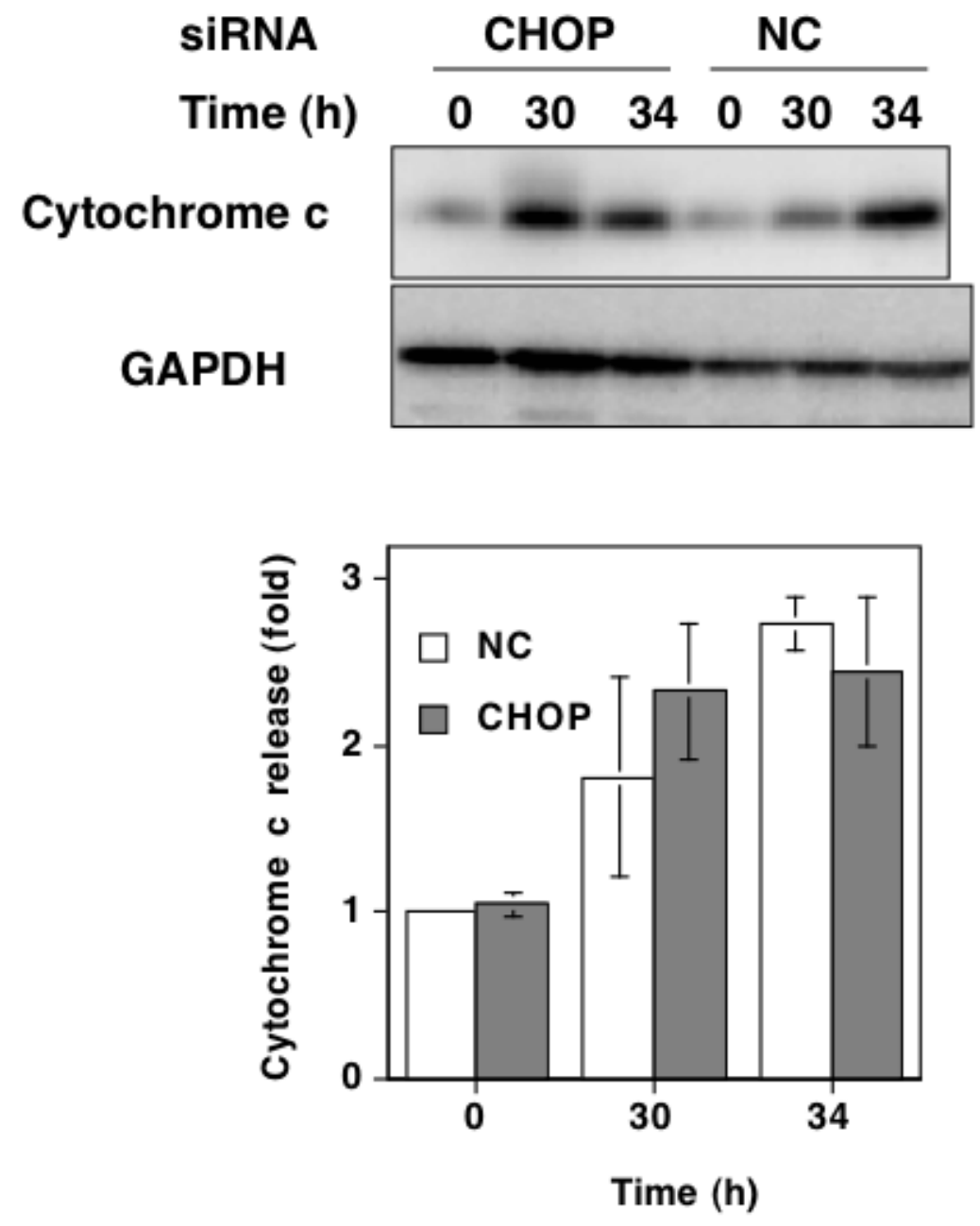
Fig. 8

B

A

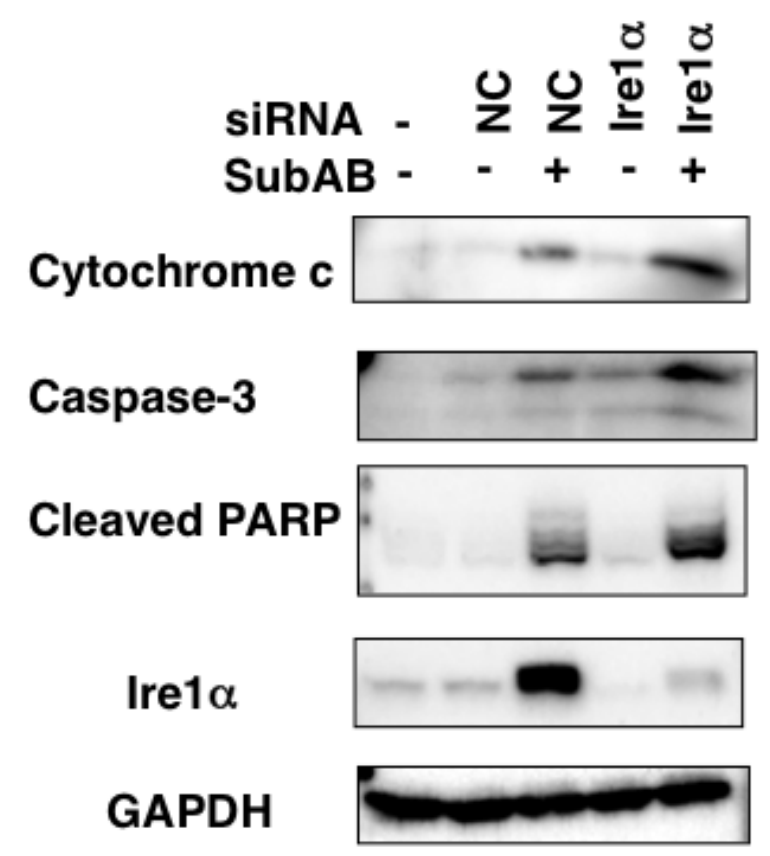


Fig.9

A SIRNA JNK NC JNK1

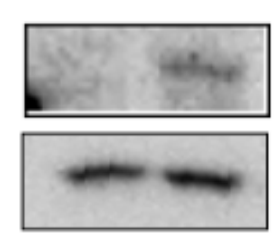

B $\begin{array}{lll}\text { SiRNA NC } & \text { JNK }\end{array}$

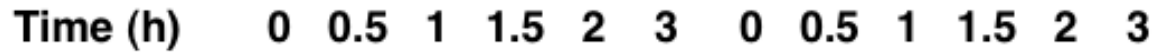
GAPDH p-JNK1 $\rightarrow$ n

C

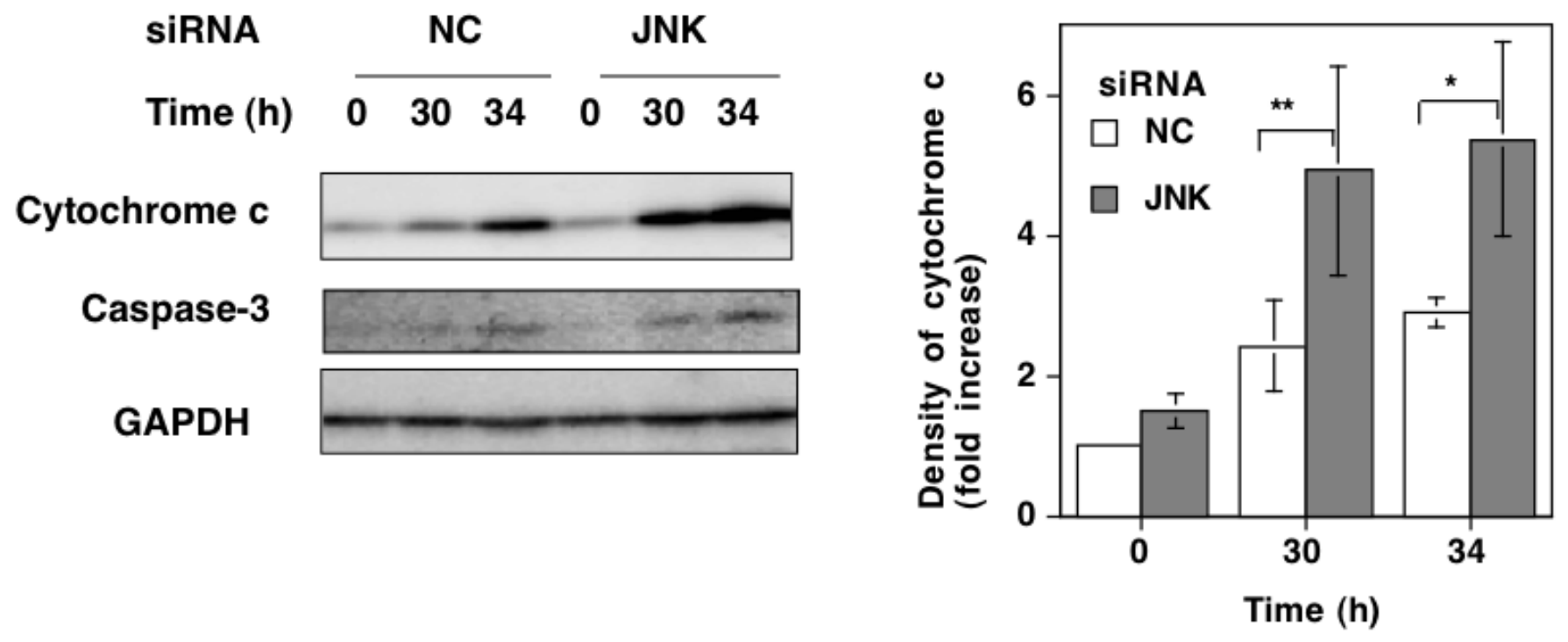


Fig. 10

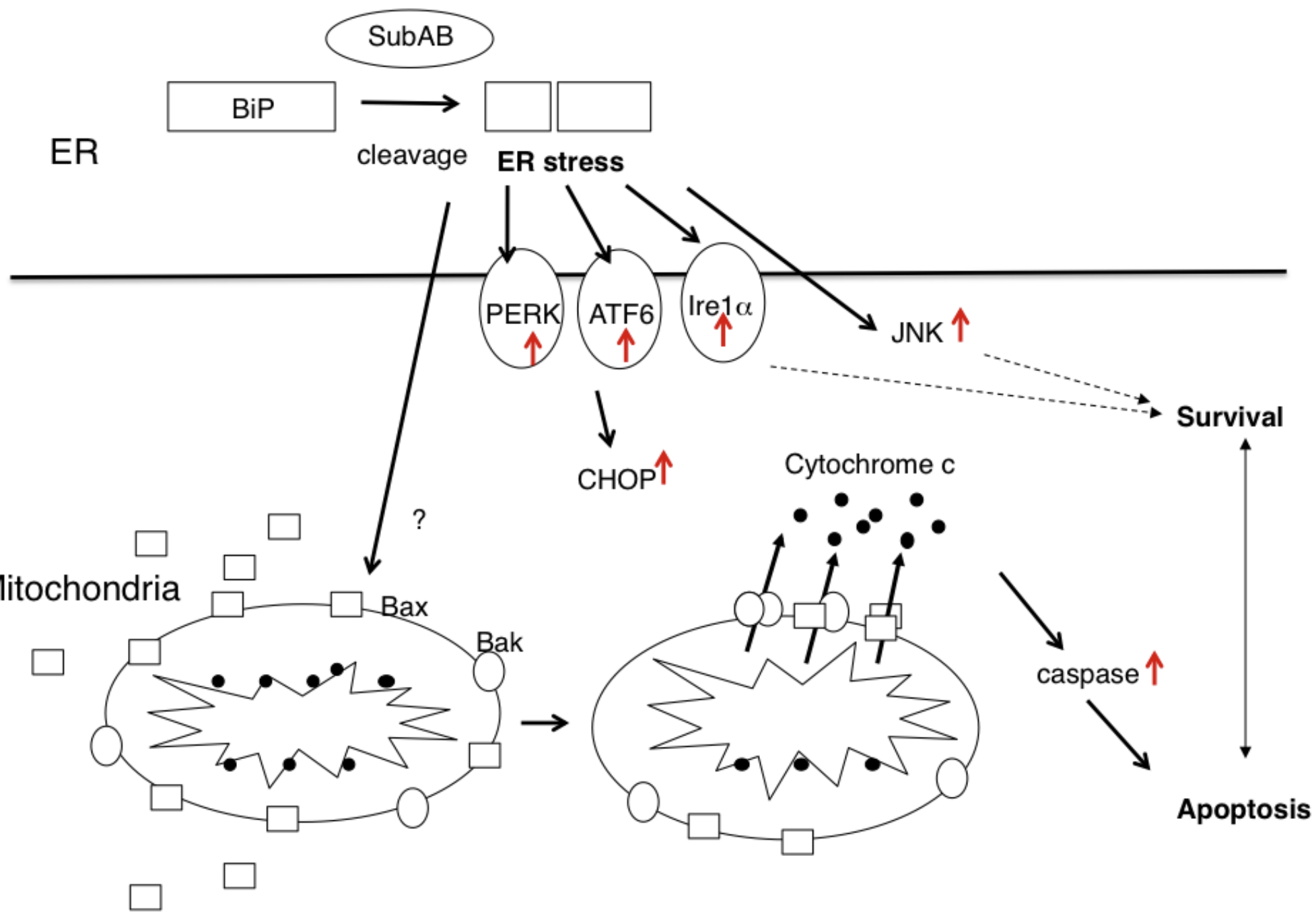


Figure S1

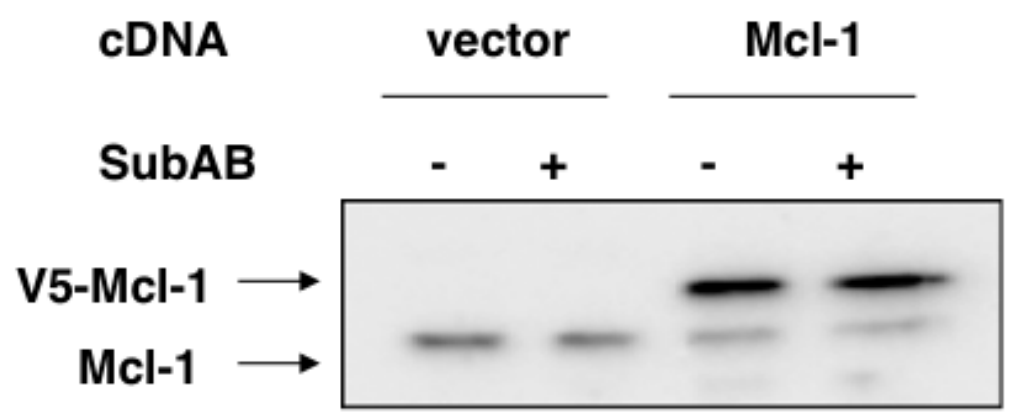

Cytochrome c

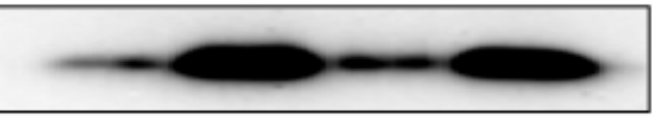

Caspase-3
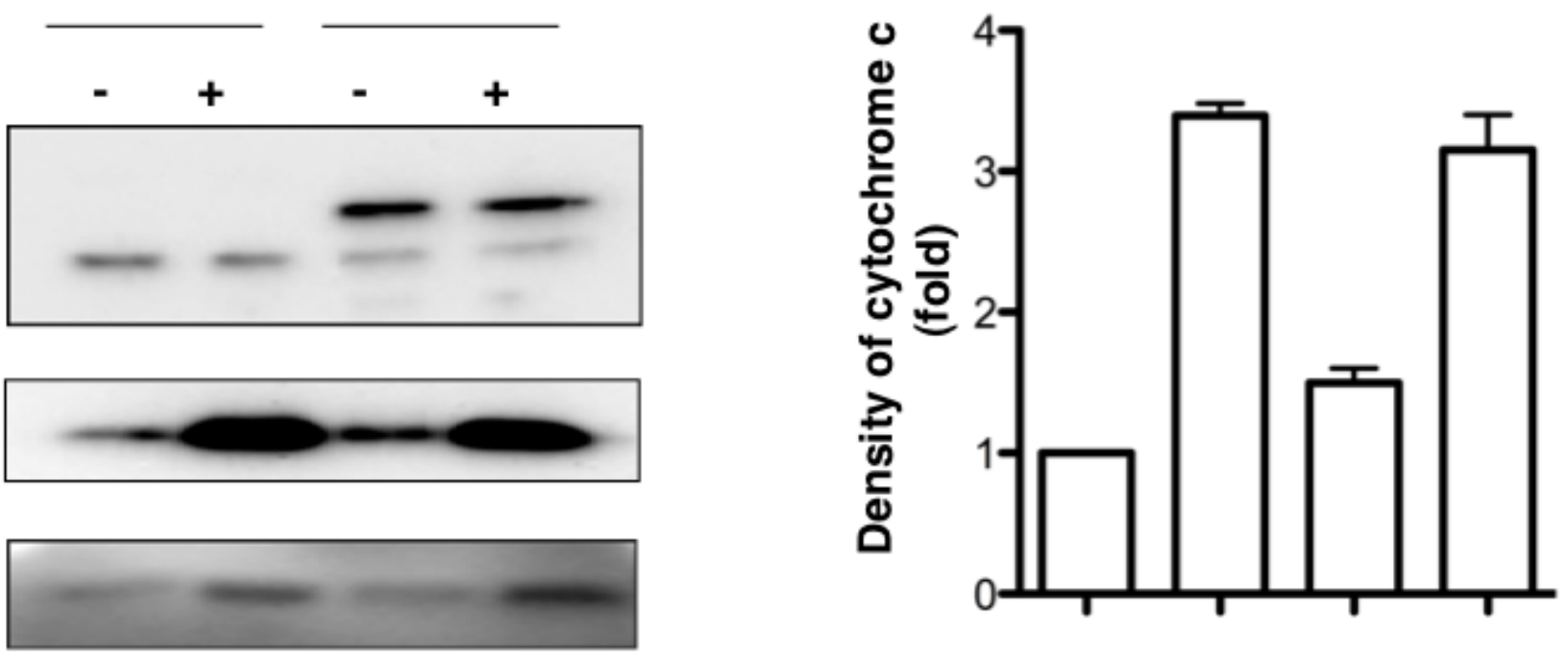

GAPDH

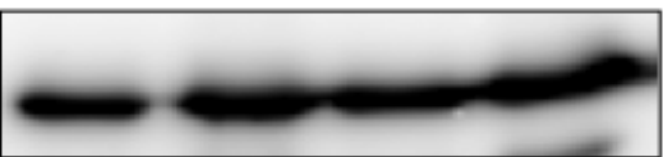


Figure S2

A

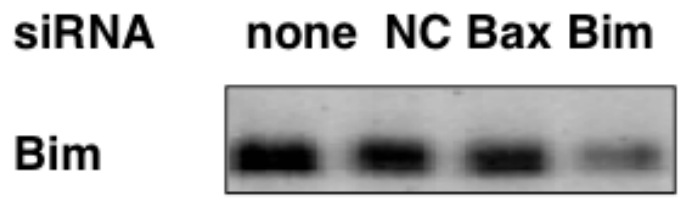

Bax

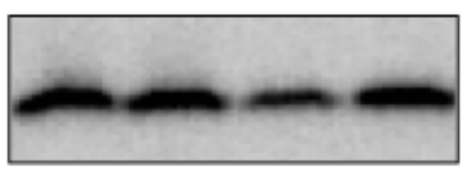

GAPDH

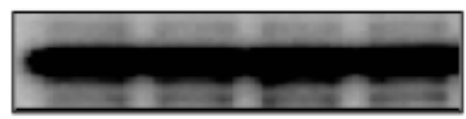

B

SubAB

siRNA none NC Bax Bim none NC Bax Bim

Cytochrome c

GAPDH
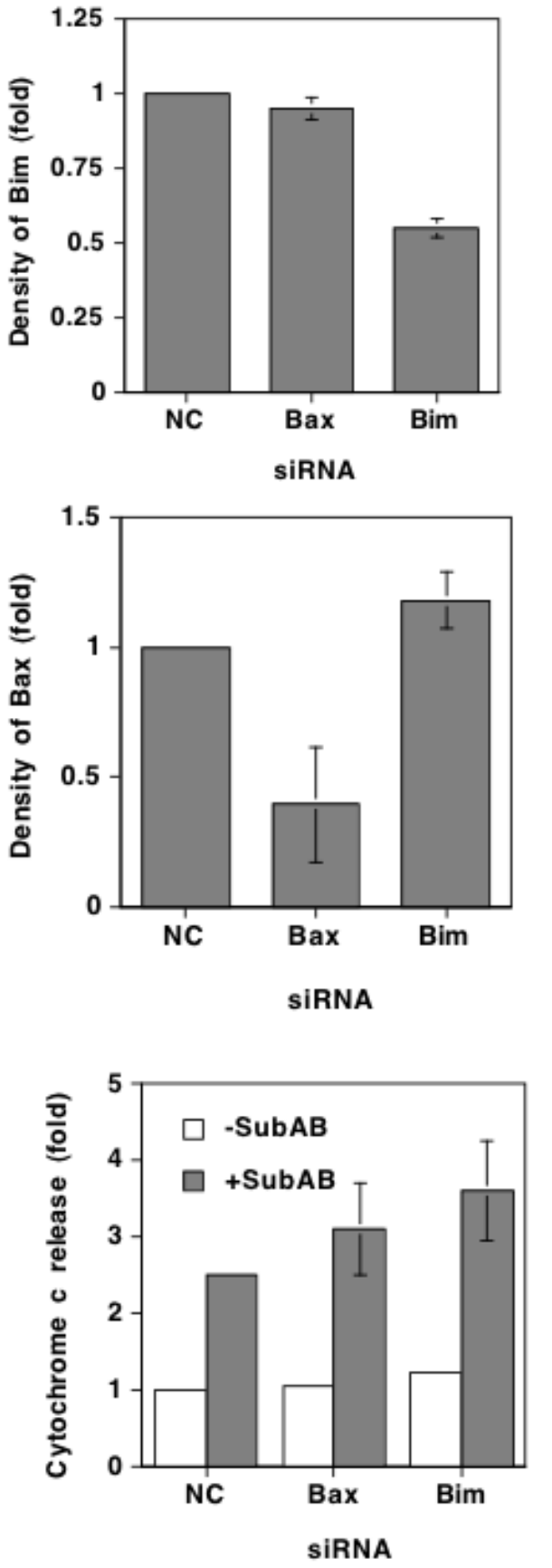
Figure S3
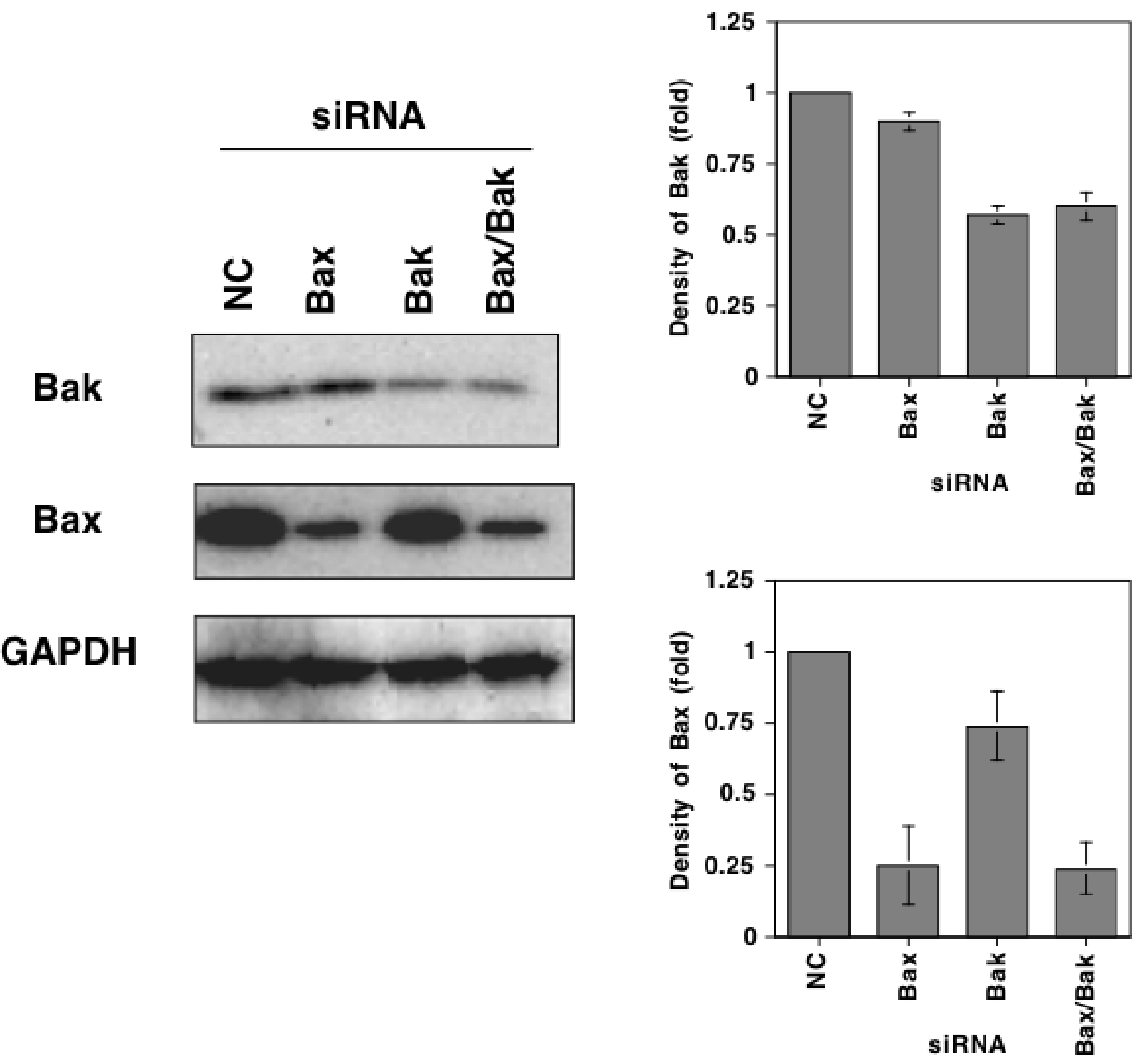